\title{
MIGRATION CREATION, DIVERSION, AND RETENTION: \\ NEW DEAL GRANTS AND MIGRATION: 1935-1940
}

\author{
Todd Sorensen \\ Price V. Fishback \\ Samuel Allen \\ Shawn E. Kantor \\ Working Paper 13491 \\ http://www.nber.org/papers/w13491 \\ NATIONAL BUREAU OF ECONOMIC RESEARCH \\ 1050 Massachusetts Avenue \\ Cambridge, MA 02138 \\ October 2007
}

The views expressed herein are those of the author(s) and do not necessarily reflect the views of the National Bureau of Economic Research.

(C) 2007 by Todd Sorensen, Price V. Fishback, Samuel Allen, and Shawn E. Kantor. All rights reserved. Short sections of text, not to exceed two paragraphs, may be quoted without explicit permission provided that full credit, including $(\mathcal{O}$ notice, is given to the source. 
Migration Creation, Diversion, and Retention: New Deal Grants and Migration: 1935-1940

Todd Sorensen, Price V. Fishback, Samuel Allen, and Shawn E. Kantor

NBER Working Paper No. 13491

October 2007

JEL No. J61,N32

\begin{abstract}
$\underline{\text { ABSTRACT }}$
During the 1930s the federal government embarked upon an ambitious series of grant programs designed to counteract the Great Depression. The amounts distributed varied widely across the country and potentially contributed to population shifts. We estimate an aggregate discrete choice model, in which household heads choose among 466 economic subregions. The structural model allows us to decompose the effects of program spending on migration into three categories: the effect of spending on keeping households in their origin (retention), the effect of pulling non-migrants out of their origin (creation), and the effect of causing migrants to substitute away from an alternative destination (diversion). An additional dollar of public works and relief spending increased net migration into an area primarily by retaining the existing population and creating new migration into the county. Only a small share of the increase in net migration rate was caused by diversion of people who had already chosen to migrate. AAA spending contributed to net out migration, primarily by creating new out migrants and repelling potential in migrants. A counterfactual analysis suggests that the uneven distribution of New Deal spending explains about twelve percent of the internal migration flows in the United States between 1935 and 1940.

Todd Sorensen

University of Arizona

sorensen@email.arizona.edu

Price V. Fishback

Department of Economics

University of Arizona

Tucson, AZ 85721

and NBER

pfishback@eller.arizona.edu

Samuel Allen

Virginia Military Institute

341 Scott Shipp Hall

Lexington, VA 24450

allensk@vmi.edu

Shawn E. Kantor

School of Social Sciences, Humanities and Arts

University of California, Merced

P.O. Box 2039

Merced, CA 95344

and NBER

skantor@ucmerced.edu
\end{abstract}




\section{Introduction}

What is the impact of federal government programs on internal migration patterns? There is a large literature in regional economics and public economics on Tiebout models where people migrate across states and counties to take advantage of differences in taxation and spending policies. Much of the literature focuses on the impact of state and local government fiscal choices and the impact of policy competition among localities. ${ }^{1}$ Yet, the federal government's distribution of funds across districts can also be extremely important. Locations of federal highways and military bases influence patterns of migration. One of the greatest experiments with federal spending in local areas occurred during the 1930s, when a wide range of New Deal grants programs were established to combat the problems arising from the Great Depression. A large literature on the political economy of that spending shows that there was substantial variation in federal grants across states and counties (see Fishback, Kantor and Wallis, 2003 for a summary).

In a recent study Fishback, Horrace, and Kantor [FHK] (2006) examined the impact of federal grants on net migration for over 3000 counties. They find that New Deal public works and relief grants stimulated net in-migration into counties and that the Agricultural Adjustment Administration's payments to farmers to take land out of production was associated with net out-migration. The FHK study, however, was limited to the study of a summary measure, net migration, and thus was unable to examine the flows of people from location to location. In this paper we use information from the 1940 Census on locations of households in 1935 and 1940 to estimate a model in which households are choosing among 466 state economic areas (SEAs). We build an aggregate dis-

\footnotetext{
${ }^{1}$ See Rhode and Strumpf (2003) for a summary of the literature and results that do not find much Tiebot sorting over long time periods in response to state and local government goods provision.
} 
crete choice model from a random utility model of locational choice to estimate the impacts of spending on these programs on migration patterns.

When we combine the structure of the model with the information on flows of migration between the SEAs, we are able to derive a series of inferences about the impact of New Deal programs on the substitution patterns of migrants between locations. We compute marginal effects of program spending that are decomposed into three distinct effects. The first is migration creation. A migrant is "created" by a program when program spending causes a household that would otherwise have remained in its 1935 location to migrate to a given location. The second, a retention effect, occurs when a migrant is "retained" because program spending causes a household that would have out-migrated otherwise to remain in the 1935 location. Finally, migration diversion results when a migrating household is diverted to another location.

The structural nature of our model also allows us to estimate counterfactuals to identify the overall effect of New Deal spending on migration, an analysis that FHK (2006) could not perform. We estimate counterfactuals for the absence of each of two major categories of New Deal spending, as well as a counterfactual for the absence of all New Deal spending. The results show that an additional dollar of public works and relief spending at the margin increased net migration into an area primarily by retaining the existing population and creating new migration into the county. Only a small share of the increase in the net migration rate was caused by diverting people who were already migrating to another place into the location. A similar story can be told about the magnitudes of the marginal effects of an added dollar of per capita AAA spending, except the direction of the effect was negative as AAA spending served to stimulate out-migration in all three ways. A counterfactual analysis that examines what would have happened had there been no New Deal spending during the 
1930s suggests that the uneven distribution of New Deal public works and relief spending explains about twelve percent of the internal migration flows in the United States between 1935 and 1940, while the uneven distribution of AAA spending accounted for about one percent.

\section{New Deal Programs}

We consider two categories of per capita New Deal grants that may have affected the desirability of a location: AAA farm grants and public works and relief grants. The AAA grants were made to farmers who voluntarily removed land from production for designated crops. ${ }^{2}$ The goal of the program was to increase the incomes of farmers, both directly through benefit payments and indirectly by raising market prices to pre World War I levels (1920s levels for tobacco), through the curtailment of the output of specific crops. ${ }^{3}$ The AAA programs

\footnotetext{
${ }^{2}$ Prior to 1936 , the first version of the AAA made rental and benefit payments to farmers who removed land from the production of designated crops. After the program was struck down as unconstitutional by the U.S. Supreme Court in 1935, the AAA was redesigned, to make "soil conservation payments" through the Soil Domestic Allotment Act (SDAA). In the original AAA the benefit payments were financed from special processing taxes on the commodity being curtailed. There was a general belief that most of the burden of the processing taxes would be passed on to consumers of farm products. After the Supreme Court declared the processing taxes unconstitutional, the SDAA eliminated the processing taxes and the funds were appropriated from the general budget.

${ }^{3}$ The AAA was administered by the Department of Agriculture, which established state and local committees or associations of producers to help administer the act. The administration of the Act was often done through a series of programs specific to the household crops. Thus the geographic distribution of the AAA funds across counties was determined by the crop choices made prior to the AAA involvement and by the parameters set for each of the crops. For each crop the actual distribution of funds was determined by a complex interaction between federal administrators, local committees, local extension agents, and the farmers who decided to join the program. Since this was a voluntary program, farmers had to agree to sign up for the acreage reduction program. For signing up to reduce acreage, their payments were based on multiplying the national price set for acreage reduction and their average yield per acre over a base period. Thus, the program had to be made attractive enough for farmers to agree to join. The federal decision makers influenced the attractiveness of the program by the national price they set for acreage reduction and by the acreage that they asked the farmers to take out of production. In the case of tobacco and cotton the federal decision-makers added a degree of coercion to the system by levying heavy taxes on any production beyond designated limits. The local administrators influenced the attractiveness of the program through decisions on base-year yields for the household farmer and the acreage the farmers would be allowed to produce. In addition, the effort they put into marketing the program and cajoling their neighbors helped determine the sign-up rates.
} 
likely had conflicting effects on migration. The farmers who received payments from the AAA were likely to stay in farming and, thus, less likely to migrate. In contrast, farm workers and tenants might have been pushed out by the AAA because the AAA payments led to reductions in acreage under cultivation, which was likely to lead to a decrease in the demand for farm workers (Alston 1981; Holley, Winston, and Woofter 1971; Saloutos 1974; Mertz 1978; Whatley 1983; Biles 1994, 39-43, Fishback, Horrace, and Kantor 2006).

New Deal funds also were distributed to local economies through public works and relief grants. Relief grants were primarily distributed under the auspices of the Federal Emergency Relief Administration (FERA) from 1933 through mid 1935, the Civil Works Administration (CWA) from November 1933 through March 1934, the Works Progress Administration (WPA) from mid 1935 through 1942, and the Social Security Administration's Aid to the Blind, Aid to Dependent Children, and Old-Age Assistance programs after 1935. The principal goal of these programs was to provide immediate relief to unemployed and low-income people, as 85 percent of the grants were used to hire the unemployed on work relief jobs. These relief jobs ranged from make-work activities to maintenance activities to the building of sidewalks, post offices, schools, local roads, and other additions to local infrastructure.

The public works grants included expenditures by the Public Works Administration (PWA), Public Buildings Administration, and the Public Roads Administration. These grants were also used largely to employ workers. Many of the workers were hired directly from the relief rolls, but the public works programs had more freedom to hire a broader class of workers who were not on relief. The public works programs were said to be more focused on building larger scale projects such as dams, roads, schools, and sanitation facilities. Both public works and relief grants were likely to attract migrants to local areas 
because they provided either work opportunities on federal projects or support for the unemployed. This effect was mitigated to the extent that local relief administrators imposed residency requirements

The major relief and public works programs had the potential to stimulate migration across counties, as the unemployed sought work in areas with new relief and public works projects. The economics literature on the impact of welfare benefits on locational choice in the modern era is mixed, some find that movement of low-income people is positively correlated to differences in states' welfare benefit levels (Gramlich and Laren 1984, Blank 1988, Moffit 1992), while others find a small or negligible effect (Allard and Danziger 2000; Kauffman and Kiesling 1997, and Levine and Zimmerman 1999). We should note that our measure of relief and public works spending is total spending per capita, so it combines both differences in the number of people obtaining funds and the monthly payments to recipients of emergency jobs or direct relief. There were federal efforts to establish a certain minimum level of benefits, but the eventual compromise between officials at all levels was to pay attention to prevailing wage levels. Faced with extraordinary unemployment rates, relief officials were forced to make trade-offs between providing adequate benefits and finding work for as many unemployed workers as possible (see Brown 1940, Howard 1943, Williams 1968, Wallis and Benjamin 1981). Given the large number of unemployed workers, access to benefits might have been as important as the actual level of benefits.

Since the public works and relief projects involved not only relief of economic distress, but also led to expansions in civil infrastructure that potentially promoted economic activity in a deeply depressed national economy, we might expect to see more of a migration response in the 1930s than we would for federal welfare programs in the modern era. The migration response during the 
Depression, however, might have been limited by a complex web of residency requirements for relief eligibility. Unlike modern federal welfare programs that have largely eliminated residency requirements since 1970 (Gramlich and Laren 1984, 490), the residency requirements of the Depression-era relief programs were determined largely by state and local governments, sometimes in ways that seemed to violate the spirit of federal statements. Donald Howard (1943, 332-7) noted that the official WPA policy as of 1939 was that eligible people could not be refused certification for work relief jobs on the basis of non-residence in the area. At the same time, the WPA did not want families moving for the "sole purpose" of obtaining a relief job. Most of the barriers to movement were erected by state and local bureaucracies, which created elaborate procedures for transferring workers' records from one state to another and required that workers reestablish their eligibility in new places, among other factors. An unemployed worker took an additional risk by moving because state and local length-of-residency requirements for direct relief and public assistance may have differed. The de facto result might have been limits on non-residents' abilities to qualify for the WPA positions. On the other hand, to the extent that work relief projects stimulated the local economy, there may have been increased private opportunities for migrants.

The FERA policies for most types of relief were similar to the later WPA policies, although the FERA explicitly provided a small portion of its funds for the transient population. Josephine Brown $(1940,250)$ noted that federal FERA policy forbade discrimination against non-residents, blacks, aliens, and veterans, "yet the fact remained that the actual administration of relief was in the hands of local authorities and the promulgation of a rule by the FERA was not sufficient in many cases to overcome sectional traditions and prejudices in a comparatively short time." Aware of this problem, the FERA formulated a transient program 
for workers with less than a year's continuous residence (Williams 1968, 172-

3). The program was funded by the federal government and administered by the states. It typically provided aid to the transient unemployed who could not have obtained aid under the legal settlement or residency requirements of the states (Webb 1936, 1-4, 16). The transient program accounted for about 2 percent of the total obligations of FERA programs (Federal Works Agency, Works Progress Administration 1942, 74 and 81), so in the final analysis the impact of FERA spending on migration patterns may not have differed much from that of the WPA. ${ }^{4}$

\section{Migration and the Location Choice Literature}

Sjaastad (1962) viewed migration as an investment in obtaining access to a labor market with higher wages. The moving costs are treated as the fixed costs of the investment while the gain in earnings is the return. A household chooses to migrate if the present value of the migration is less than the cost of undertaking it. In his adaptation of the Roy (1951) model, Borjas et al.(1992) develops a theoretical model predicting that households will sort themselves into regions paying the highest return to their skills. They find that individuals who face a mismatch between their skills and rewards to their skills are more likely to migrate, i.e. highly educated individuals living in states with a relatively low return to education will migrate to a state with higher returns to education.

Later papers in the literature apply discrete choice models to location choice among migrants. A seminal paper in this literature was Bartel (1989), which studies the secondary migration choices of international migrants. In the context of a location choice model, she estimates the effects of ethnicity, population,

\footnotetext{
${ }^{4}$ The Civilian Conservation Corps often moved young men across states, but we do not have county level information on the CCC and, thus, cannot measure its impact in this study.
} 
social welfare programs, and distance on the probability of moving to a particular destination. She finds that the level of general assistance payments in a destination is positively and significantly correlated with a migrants probability of choosing the destination.

Schaefer (1989) analyzes location choices in the southern United States in the 1850 's to examine non-slave owners' preferences over the racial composition of a destination county. Jaeger (2000) studies the location choice of newly arrived international migrants. He finds that migrants are more likely to locate in areas with disproportionately high foreign born populations. Herzog and Schlottmann (1986) used a binary logit model to study how amenities weigh in the decision to migrate or stay. Cragg and Kahn (1997) also use a conditional logit model of the destination choice of migrants. The structural nature of this model allows them to calculate migrants' willingness to pay for climate characteristics.

The common thread of these papers is the estimation of a discrete choice model that leads to a structural interpretation of the parameters, allowing the researcher to answer various questions, which could not be addressed in nonstructural models. In this paper we estimate structural model of migration in order to calculate effects of New Deal spending on migration patterns which would not be computed for a linear model of net migration.

\section{Data}

The data set is built up from a variety of sources, but we will focus on two sources here. The U.S. Office of Government Reports (1940) reported the distribution of New Deal grants for public works, relief programs, and AAA payments across counties. Meanwhile, the 1940 Population Census was the first decennial census to ask respondents about their place of residence in preceding years, in this case 1935. While information on previous county of residence is not available from 
the IPUMS, we are able to identify the "state economic area" (SEA) where the respondent resided in $1935 . .^{5}$ Our sample consists of all native households for which location variables were available, giving us a total of 337,803 observations. We observe 466 SEA's that fully cover the continental states, excluding Washington, D.C, and the Alaska and Hawaii territories. In order to measure rates of migration, we construct a Markov transition matrix using the IPUMS extract of the 1940 Census 5 percent microsample. ${ }^{6}$

Figures 1 through 3 show that there is a significant amount of variation in migration rates and New Deal programs that can be used to identify the effects of the New Deal grants. Figure 1 plots the in-migration and out-migration per 100 people in 1930 for each of the SEAs. The figure shows quite a bit of variation in both types of migration rates and only hints at the information we use in estimating the model because it does not show the flows between SEAS, which are a key part of our model. Figures 2 and 3 plot the net-migration rates against public works and relief grants per capita and AAA grants per capita. Net migration rates range from -20 percent to nearly 40 percent of the 1930 population in the SEAs, while public works and relief spending per capita varies from close to zero in some SEAS to over $\$ 300$ per capita in some locations. The AAA distribution of grants was not as dispersed, but there still remains an extensive spread.

\footnotetext{
${ }^{5}$ The SEAs were developed by Donald Bogue to combine "relatively homogeneous" counties within a state (See Bogue and Beale (1953) and Bogue (1951). Bogue led a research team that analyzed how individual characteristics influenced the migration patterns across these regions. For example, see Bogue, et. al. (1957).

${ }^{6} \mathrm{~A}$ complete description of the sources of the New Deal spending variables and demographic, geographic, and economic characteristics of SEAs can be found at Price Fishback's website, http://www.u.arizona.edu/ ${ }^{\sim}$ fishback/ in the information on the construction of varaibles for the Fishback, Horrace, and Kantor (2005a, 2005b, 2006) migration and retail sales papers. The county-level data underlying the SEA aggregates for this study can be found there.
} 


\section{Identifying Program Effects}

Our evaluation of the impact of New Deal spending is built up from a structural model of household choice. We start with a model of individual household choices and then show how an aggregate discrete choice model-one that uses shares of households making a decision rather than discrete decisions of individual households-can be used to estimate the parameters of this model.

\subsection{Household Decision Model (CLOGIT)}

Each household in our sample resided in one of 466 "State Economic Areas" in 1935. Between 1935 and 1940, each of these households decided where to locate in 1940: in the 1935 location, or in one of the 465 other SEAs in the country. Consider the following utility function for households.

$$
U_{i j}=X_{o j} \beta+\xi_{o j}+\varepsilon_{i j}
$$

The term $U_{i j}$ represents the utility to the $i^{\text {th }}$ household of residing in the $j^{\text {th }}$ location in 1940. The utility for households from origin $o$ is determined by the characteristics of the location $j$ to households from origin $o, X_{o j}$. The product $X_{o j} \beta$ represents the utility the household receives from these characteristics, where $\beta$ is a vector of marginal utilities.

The purpose for including the subscript $o$ is that characteristics of locations, such as distance, will differ across origins. For example, the distance between Southern California and Northern California is significantly lower than the distance between Florida and Northern California. If we assume that the utility of distance traveled, $\beta_{\text {Distance }}$, is negative, then

$$
X_{\text {NorCal,SoCal }} \cdot \beta_{\text {Distance }}>X_{\text {Florid,SoCal }} \cdot \beta_{\text {Distance }}
$$


Thus, because one of the characteristics of Southern California as a migration destination (distance), varies between two different origins, Northern California and Florida, the utility of the location will differ across origins. Note however, that this utility does not differ among households from a common origin: the term $X_{o j} \beta$ assigns the same level of utility of locating in location $j$ to all households from origin $o$.

Simply specifying the utility of the location as $X_{o j} \beta$ is unreasonable in two ways. First, it assumes that all characteristics that influence the decision of the household are observed by the econometrician. This assumption can be relaxed by introducing an error term that represents the utility of the location derived from characteristics observed by the household but not by the econometrician, $\xi_{o j}$.

While the introduction of the $\xi_{o j}$ term eliminates the "omnipotent econometrician" assumption, the model still has one unreasonable property. It predicts that households from a common origin will all make the same location decision because the term $X_{o j} \beta+\xi_{o j}$ does not vary among households within the origin. The common way to relax this assumption is to introduce a random error term $\varepsilon_{i j}$ that varies across both households and locations. These $\varepsilon$ terms can be thought of as random draws from a distribution of consumer tastes in a population. Because these draws introduce heterogeneity into the model, all households from a common origin will no longer make the same locational choice. For example, suppose household 1 has a high unobservable taste for location 6 , while household 2 does not. The difference implies that $\varepsilon_{16}>\varepsilon_{26}$, thus $U_{16}>U_{26}$.

The standard assumption about these error terms is that they are identically and independently distributed across both $i$ and $j$. The $\varepsilon$ terms are assumed to be from a Type One Extreme Value Distribution, which we discuss further 
below. This framework allows us to address the utility maximization problem in a way that is econometrically convenient while still making reasonable assumptions about consumer preferences.

The household chooses from the set of 466 destinations the location which provides the highest level of utility. Location $j$ will be the utility maximizing location if

$$
U_{i j}>U_{i k} \forall j \neq k
$$

In terms of our model, we can express this term as

$$
X_{o j} \beta+\xi_{o j}+\varepsilon_{i j}>X_{o k} \beta+\xi_{o k}+\varepsilon_{i k} \forall j \neq k
$$

Isolating the "idiosyncratic taste" terms $\varepsilon$ on the left hand side

$$
\varepsilon_{i j}-\varepsilon_{i k}>X_{o k} \beta-X_{o j} \beta+\xi_{o k}-\xi_{o j} \forall j \neq k
$$

The probability that the household will choose location $j$ is then

$$
\begin{aligned}
\operatorname{Pr}\left(U_{i j}\right. & \left.>U_{i k}\right) \forall j \neq k \\
\operatorname{Pr}\left(\varepsilon_{i j}-\varepsilon_{i k}\right. & \left.>X_{o k} \beta-X_{o j} \beta+\xi_{o k}-\xi_{o j}\right) \forall j \neq k
\end{aligned}
$$

The payoff to the distributional assumption about $\varepsilon$ comes from the result that the difference between two draws from the Type One Extreme Value Distribution takes the logistic distribution. Define the indicator variable $Y_{i j}$ as a variable that takes on a value of 1 if household $i$ chooses location $j$ and 0 otherwise. McFadden (1973) shows that by integrating out over the distribution 
of the logistic distribution, we can obtain the following probabilities:

$$
\operatorname{Pr}\left(Y_{i j}=1\right)=\frac{\exp \left(X_{o j} \beta+\xi_{o j}\right)}{\sum_{J=1}^{J} \exp \left(X_{o j} \beta+\xi_{o j}\right)}
$$

Using this property of the model, we can construct the following likelihood function for $\beta$ :

$$
\ln L(\beta \mid Y, X, \xi)=\sum_{i=1}^{N} \sum_{j=1}^{J} Y_{i j} \cdot \frac{\exp \left(X_{o j} \beta+\xi_{o j}\right)}{\sum_{J=1}^{J} \exp \left(X_{o j} \beta+\xi_{o j}\right)}
$$

This is equivalent to McFadden's choice model (Conditional Logit) with one important distinction: McFadden does not consider the $\xi$ term. If the true value of $\xi$ were known, it could be treated as an observable. However, because $\xi$ is an unknown stochastic term, like the $\varepsilon$ terms, we must integrate out over its distribution:

$$
\ln L(\beta \mid Y, X, \xi)=\sum_{i=1}^{N} \sum_{j=1}^{J} Y_{i j} \cdot \int_{-\infty}^{\infty} \frac{\exp \left(X_{o j} \beta+\xi_{o j}\right)}{\sum_{J=1}^{J} \exp \left(X_{o j} \beta+\xi_{o j}\right)} \partial \xi
$$

One important distinction between the $\xi$ and $\varepsilon$ terms is that we cannot obtain an analytical integral over the distribution of both variables. Hence we would have to compute the integral over $\xi$ using numeric methods. This is most commonly accomplished through simulation. Taking simulation draws $s=1,2 \ldots, N S$ from the distribution of $\xi$, we can compute the average of the likelihood function at these simulated draws and then estimate the parameters by maximizing the analytical portion of the likelihood function:

$$
\ln L(\beta \mid Y, X, \xi)=\sum_{s=1}^{N S} \sum_{i=1}^{N} \sum_{j=1}^{J} \frac{Y_{i j}}{N S} \cdot \frac{\exp \left(X_{o j} \beta+\xi_{s o j}\right)}{\sum_{J=1}^{J} \exp \left(X_{o j} \beta+\xi_{s o j}\right)}
$$




\subsubsection{Relaxing the i.i.d. Assumption in the Household Decision Model (NLOGIT):}

One problematic assumption made in this type of model is that the $\varepsilon$ terms are $i . i . d$. across $j$. This assumption implies that the idiosyncratic taste for one option in the choice set contains no information about the idiosyncratic tastes for other locations. This would be an unreasonable assumption if we believe that a household with a strong taste for a location such as Southern Arizona would not also be likely to have a high taste for a similar neighboring region, such as Central Arizona. If this assumption is violated, the integration McFadden uses to obtain the probabilities used in the likelihood function is invalid, and the model is mispecified.

One way to address this problem is to create a set of choices among which we expect there to be correlated tastes. For example, individuals who have a high unobservable utility from migrating to an SEA in one state may be more likely to have a high unobservable utility draw to migrating to any other SEA within the same state. Here, to account for this issue, we group choices by state. While the model maintains the assumption that the households' $\varepsilon$ draws are independent among locations in different states, we allow there to be correlation among locations within a given state.

Cardell (1997) develops a model based on a random utility function that allows for "within group" correlation while maintaining the assumption of i.i.d. draws outside of the groups. Cardell expresses the idiosyncratic utility term as a weighted average of a term that is i.i.d over $j$, and a term which is common among choices in a group $g_{j}$ (a given state).

$$
U_{i j}=X_{o j} \beta+\xi_{o j}+\sigma \zeta_{i g_{j}}+(1-\sigma) \varepsilon_{i j}
$$

For notational convenience in the following example, define the total idio- 
syncratic utility of the choice as.

$$
\varphi_{i j}=\sigma \zeta_{i g_{j}}+(1-\sigma) \varepsilon_{i j}
$$

The natural interpretation of the term $\sigma$ is a measure of how strong the "within" state correlation among the $\varphi$ terms are. When $\sigma$ is equal to 1 , the idiosyncratic utility term is identical among all locations within the state.

If $\sigma$ is equal to zero, there will be no within group correlation in the $\varphi$ terms. A $\sigma$ close to zero suggests that there is no correlation between unmeasured and stochastic factors in the same state; therefore, a household will be almost equally likely to choose a location outside the state as one inside the state, conditional upon observables. In other words, there is little reason to nest the choices at the state level in a conditional logit.

Consider how this model allows for correlation in the $\varphi$ terms for two locations in the same state:

$$
\begin{aligned}
\operatorname{Cov}\left(\varphi_{i j}, \varphi_{i k} \| k\right. & \in g \cap j \in g]) \\
& \left.=E\left\{\left[\sigma \zeta_{i g}+(1-\sigma) \varepsilon_{i j}\right]\left[\sigma \zeta_{i g}+(1-\sigma) \varepsilon_{i k}\right] \mid k \in g \cap j \in g\right]\right\} \\
& =E\left\{\sigma^{2} \zeta_{i g}^{2}\right\} \\
& =\sigma^{2} \cdot \sigma_{\xi}^{2}
\end{aligned}
$$

Note, however, that there is no covariance between two terms that are not in the same state:

$$
\begin{aligned}
\operatorname{Cov}\left(\varphi_{i j}, \varphi_{i k} \| k\right. & \notin g \cap j \in g]) \\
& \left.=E\left\{\left[\sigma \zeta_{i g}+(1-\sigma) \varepsilon_{i j}\right] *\left[\sigma \zeta_{i g}+(1-\sigma) \varepsilon_{i k}\right] \mid k \notin g \cap j \in g\right]\right\} \\
& =0
\end{aligned}
$$


The probability of observing household $i$ choosing location $j$ now becomes the product of two terms. The first is the probability of household $i$ choosing location $j$ conditional upon choosing one of the locations in the same state as $j$, while the second term is the probability of the household choosing any SEA in the state to which SEA $j$ belongs. Note that for a $\sigma$ value of 0 , this likelihood function is identical to that of the equation 10 .

$$
\begin{aligned}
\operatorname{Pr}\left(Y_{i j}\right. & =1)=\operatorname{Pr}\left(Y_{i j \mid g_{j}}=1\right) * \operatorname{Pr}\left(Y_{i g_{j}}=1\right) \\
& =\frac{\exp \left(\frac{X_{i j} \beta}{1-\sigma}\right)}{\sum_{j \in g_{j}} \exp \left(\frac{X_{i j} \beta}{1-\sigma}\right)} * \frac{\left[\sum_{j \in G_{j}} \exp \left(\frac{X_{i j} \beta}{1-\sigma}\right)\right]^{1-\sigma}}{\sum_{g=1}^{G}\left[\sum_{j \in g_{j}} \exp \left(\frac{X_{i j} \beta}{1-\sigma}\right)\right]^{1-\sigma}}
\end{aligned}
$$

\subsubsection{Complications to the Household Decision Model:}

There are a number of significant challenges to implementing this estimator, particularly when trying to resolve problems with potential endogeneity of the New Deal programs; therefore, we identify the parameters of the random utility function using the aggregate discrete choice model, rather than household data.

One problem with using individual households as the unit of observation is the sheer number of observations. The census data we use contains observations on the location choice of 337,803 households choosing between 466 SEAs. At each iteration of the MLE estimation, this would require over 150 million computations of the location specific utility for each household. For each of these 150 million calculations, our model would also require us to numerically integrate out over the $\xi$ term using simulation methods. Clearly, this approach to estimation involves significant computational burdens.

An additional issue we must address is the possible endogeneity of New Deal program spending. From a statistical standpoint, it would be ideal if the 
New Deal grants were distributed on a random basis and, thus, could serve as a natural experiment. Of course, there is plenty of evidence that the New Deal grants were not distributed in a random fashion across areas. More per capita relief grants were distributed to areas with higher unemployment and greater drops in economic activity between 1929 and 1933 (Fishback, Kantor and Wallis 2003). Although we control for some of these factors, we still need to worry about potential endogeneity bias in the coefficients if the New Deal grants were distributed in response to unmeasured characteristics of the location that influenced the attractiveness of the location to migrants. Instrumenting for program spending in the household based model would involve fully specifying the data generating process for $\xi$ and integrating out over its distribution. A significant advantage of the aggregate discrete choice model is that it will allow us to instrument for New Deal grants using two-stage-least-squares (2SLS).

\subsection{Using an Aggregate Discrete Choice Model}

An alternative to estimating the household discrete choice model is the use of an aggregate discrete choice model, which is free of the complications of the prior model. The seminal paper developing this methodology is Berry (1994). Over the last ten years, the "Berry Inversion" has become common in the empirical industrial organization literature.

Recall the probabilities in the likelihood function for the conditional logit model:

$$
\operatorname{Pr}\left(Y_{i j}=1\right)=\frac{\exp \left(X_{o j} \beta+\xi_{o j}\right)}{\sum_{J=1}^{J} \exp \left(X_{o j} \beta+\xi_{o j}\right)}
$$

Note that the the right hand term varies across $o$, but not across $i$. In this model individuals from the same origin have equal chances of migrating to location $j$. 
Accordingly, the probability that an individual from $o$ moves to $j$ can also be interpreted as the share of individuals from $o$ moving to $j$. Define $s_{o j}$ as the share of households from origin $o$ moving to location $j$.

$$
s_{o j}=\operatorname{Pr}\left(Y_{i j}=1\right)=\frac{\exp \left(X_{o j} \beta+\xi_{o j}\right)}{\sum_{j=1}^{J} \exp \left(X_{o j} \beta+\xi_{o j}\right)}
$$

Similarly, we can define the share of households from origin $o$ who remain in the origin, $s_{o o}$, as

$$
s_{o o}=\operatorname{Pr}\left(Y_{i o}=1\right)=\frac{\exp \left(X_{o o} \beta+\xi_{o o}\right)}{\sum_{j=1}^{J} \exp \left(X_{o j} \beta+\xi_{o j}\right)}
$$

The $\log$ of the ratio of the terms in 17 and 18 is then

$$
\begin{aligned}
\ln \left(\frac{s_{o j}}{s_{o o}}\right) & =\ln \left(\frac{\frac{\exp \left(X_{o j} \beta+\xi_{o j}\right)}{\sum_{j=1}^{J} \exp \left(X_{o j} \beta+\xi_{o j}\right)}}{\frac{\exp \left(X_{o o} \beta+\xi_{o o}\right)}{\sum_{j=1}^{J} \exp \left(X_{o j} \beta+\xi_{j}\right)}}\right) \\
& =\ln \left(\frac{\exp \left(X_{o j} \beta+\xi_{o j}\right)}{\exp \left(X_{o o} \beta+\xi_{o o}\right)}\right) \\
& =\left(X_{o j}-X_{o o}\right) \beta+\left(\xi_{o j}-\xi_{o o}\right)
\end{aligned}
$$

We observe choices made by households in 466 SEAs. Each of these households chooses between the 466 locations in their choice set. The information needed to construct our dependent variable is essentially a transformation of a Markov transition matrix, (represented below) summarizing the movement of households among 466 locations between 1935 and 1940. Rather than requiring over 150 million computations (excluding the simulations over $\xi$ ) we now have $466^{*} 465=216690$. The 466 cells along the diagonal of the matrix are the $s_{o o}$ terms used in the normalization. Note that the model is now invertible in $\xi$; 
this is a key result which will allow us to estimate the parameters of the random utility function using conventional linear methods, such as 2SLS to instrument for endogenous $X$ variables.

$$
\begin{aligned}
& \text { Migration Markov Transition Matrix }
\end{aligned}
$$

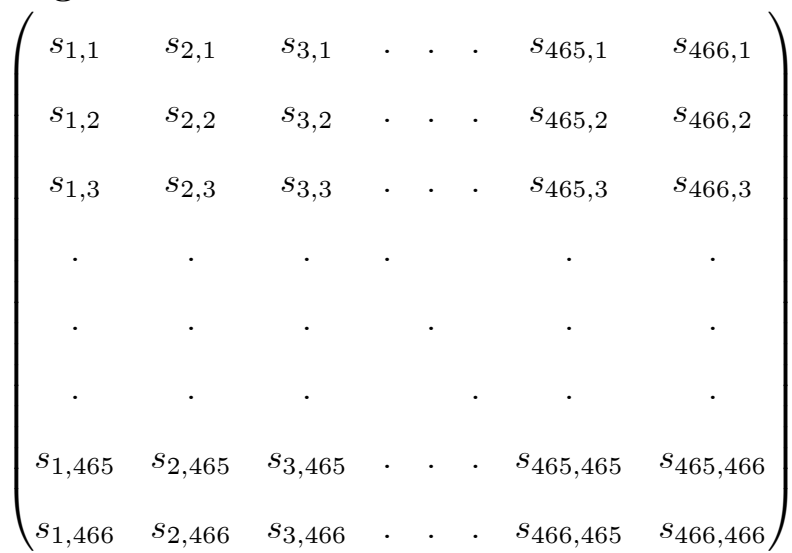

\subsubsection{Relaxing the i.i.d. Assumption in the Aggregate Discrete Choice Model:}

Berry (1994) also derives an inversion of the nested logit model, whose likelihood function is given in equation 15. In his paper, the inversion relies upon an assumption that the "outside alternative" is a group to itself. In our model groups are states and the households' "outside alternative" is to choose not to migrate. Berry's assumption does not hold in our case as the option of staying in the home SEA is just one of several choices available for the household that chooses to remain in the home state (the group containing the "outside alternative"). In Appendix I we invert the nested likelihood model without relying upon this assumption, arriving at the same result as Berry. The additional term is the log of the share of the households from origin $o$ choosing location $j$, conditional upon choosing one of the SEAs in the same state as $j$.

$$
\ln \left(\frac{s_{o j}}{s_{o o}}\right)=\left(X_{o j}-X_{o o}\right) \beta+\sigma \cdot \ln \left(s_{o j \mid g_{j}}\right)+\left(\xi_{o j}-\xi_{o o}\right)
$$




\subsubsection{Instrumenting for New Deal Spending:}

Because migration flows, or unobserved variables correlated with migration, might have influenced the distribution of New Deal grants, there might be endogeneity bias in the coefficients on the New Deal variables. A priori, it is difficult to predict the direction or magnitude of the endogeneity bias. If outmigration was associated with economic distress during the 1930s, local officials may have sought greater New Deal funds from the federal government to alleviate the local unemployment situation and to stave off a continuing exodus of the workforce. Roosevelt's "relief, recovery, and reform" mantra would suggest that federal officials targeted funds to alleviate such economic problems. In fact, Fleck (1999a, 1999b, 2001a) and Fishback, Kantor, and Wallis (2003) find that both relief and public works spending were positively related to unemployment in 1930. To the extent that out-migration was a symptom of unmeasured unfavorable economic conditions, we might expect federal officials to have distributed more funds to areas where people were more likely to leave than to arrive. Thus, the endogeneity bias might have been negative, causing the OLS coefficient to understate a positive effect that public works and relief spending might have had in attracting migrants.

Alternatively, the endogeneity bias could have gone the other way. Increased in-migration placed greater pressure on public facilities, such as schools and sanitation and water systems, which would have encouraged local officials to lobby for New Deal projects that would have alleviated these population pressures. In addition, if migrants into a county misestimated the employment opportunities in their new homes, their arrival might have contributed to greater unemployment and the need for federal New Deal assistance. However, the tendency for

local relief officials to restrict non-residents' relief certification was likely to have mitigated this effect. 
It is also likely that the AAA variable is endogenous, but the direction of the bias is unclear. Unlike the relief programs, the objective of the AAA was to limit national production of various commodities to raise farm-gate prices. The parameters were designed with national prices and production in mind and, therefore, were not explicitly tied to local problems. The officials' parameter choices, however, might have been indirectly influenced by local conditions because national AAA parameters depended on the need to raise prices for specific crops. Since crop mix varied substantially across the country and the distress in specific crops may have been felt more heavily in some areas than in others, local agricultural conditions may have indirectly influenced the policy parameters that determined the distribution of AAA funds. Thus, to the extent AAA officials were seeking to raise prices by reducing production, they may have seen reductions in production caused by the out-migration of farmers as a means in itself to limit supply and, thus, saw less of a need to provide AAA funds. Under these conditions, the OLS coefficient of the AAA variable is likely biased in a positive direction. On the other hand, federal officials may have seen outmigration as a sign of distress and, thus, more reason to find ways to prop up farmers in those areas. In this case the OLS coefficient would be biased in a negative direction.

One of the key advantages of the share-based model is that we can instrument for endogenous variables using the standard Two-Stage Least Squares (2SLS) procedure. Relevant and valid instruments are correlated with the level of New Deal spending but uncorrelated with unobservables affecting the utility of the location.

There is an extensive literature on the political economy of the supply of New Deal program spending. ${ }^{7}$ Robert Fleck (1999a), Fishback, Haines, and

\footnotetext{
${ }^{7}$ For discussions of the determinants of New Deal spending, see Reading 1973; Wright 1974; Wallis 1987, 1998, and 2001; Anderson and Tollison 1991; Couch and Shughart 1998; Couch, Atkinson, and Wells, 1998; Fleck 1999a, 1999b, 2001a, 2001b; Couch and Williams
} 
Kantor (2001), and Fishback, Horrace, and Kantor (2005b, 2006) have had success using some of these political supply variables as instruments in studies of unemployment statistics, birth and death rates, retail sales growth, and net migration. Based on these studies, the political supply equation for New Deal spending includes quite a few factors that likely influenced the household's choice to migrate to a location. These might include the typical party affiliations, the long-term structural features of the economy, the size of the population, the ethnic structure of the population, opportunities for home ownership and other socioeconomic factors. These factors are already incorporated in the vector of attributes associated with locations in the migration share analysis. There are other factors, however, that either would not be expected to influence the attractiveness of locations to migrants, or would have influence only indirectly through incomes and the other socioeconomic factors already included as attributes in the migration analysis.

There are two New Deal political supply factors that potentially influenced public works and relief spending but would have only indirectly influenced the choice to migrate to a location, the land area in the SEA and the standard deviation of the percent voting for the Democratic presidential candidate over the period 1896 through 1928. Land area and population were key factors in the formula for distributing road funding and larger counties and states in terms of square mileage tended to receive larger Public Works Administration grants (Fleck 2001b, Fishback, Kantor, and Wallis, 2003). The size of the SEAs in square miles is determined by the counties' geographic boundaries, which were typically set long before the 1930s, and Bogue's (1951) combination of counties into relatively homogeneous SEAs. After controlling for a wide variety of socioeconomic factors and for in-variant state effects, there is no apparent

1999; Stromberg 2004. Fishback, Kantor, and Wallis 2003. The last paper summarizes the results of all of the studies and provides new estimates for a broad range of programs.. 
reason why migrants would have additional reasons to care about the amount of land in the county boundaries and then how many were grouped into the SEAs. Since county boundaries (and thus economic sub-region boundaries) often extended well beyond populated areas, the land area of the county would not be an effective measure of the population density of a city and thus would not be expected to appear in the migration decision.

Nearly all of the studies of the distribution of New Deal funds find that the Roosevelt administration spent more in areas where there was greater swing voting in presidential elections. Wright (1974), Wallis (1987, 1998, 2001), Fleck (2001, 1999a), Couch and Shughart (1998) and several other scholars use the standard deviation of the percent voting Democrat for president over a prior period as a measure of swing voting. There is already temporal distance between the migration decisions from 1935 to 1940 and the standard deviation measure from 1896 to 1928. In the final migration equation we have already controlled for political attitudes using the mean voting Democrat for president from 1896-1928 and state fixed effects of the destination, and subregion of origin fixed effects, as well as a variety of other socioeconomic dimensions. It seems unlikely that people would be paying attention to the swing voting issue in their migration decisions once we have controlled for these factors.

In addition, we include a key political supply variable that influenced AAA spending but at best would have influenced migration decisions only indirectly through other channels that we have controlled for in the analysis: average farm size in 1929. Average farm size strongly influenced the AAA distribution at the county level (Fishback, Horrace, and Kantor 2006; Fishback, Kantor, and Wallis 2003). The AAA has always been focused on large farms. The average farm size measure is for the period prior to the New Deal and thus farmers had no opportunity to change this size in anticipation of obtaining New 
Deal funds. Farm size, per se, would not have been a factor that would have attracted or repelled migrations. It would have influenced migration patterns by influencing the distribution of AAA funds, farm income, crop failures, and farm productivity. These are all factors that we control for in the estimation of the migration equation. We control for measures of income and wealth using the level and growth rate of retail sales per capita, the home ownership percentage, racial and ethnic shares of the population, and layoffs and unemployment. We control for farm productivity and farm success using crop output per person, and crop failures. We also control for the extent of farming with the percentage of the rural population on farms. In addition, we incorporate a series of state effects and subregion of origin effects that control for a variety of characteristics of soil, climate, and other factors that might have influenced farm size and migration decisions.

Since the true errors in the migration share equation are unknown by definition, we can never be sure that these identifying instruments are uncorrelated with the error term. We can, however, use the Hansen J-statistic to test for correlation between the identifying instruments and the estimated error term in the migration share equations.

The first-stage equations in Table 2 show that the coefficients of all of the identifying instruments have the expected sign. Larger SEA land area and the standard deviation of the percent voting Democrat for president were associated with higher than average per capita public works and relief spending in the SEA. Larger average farm size in 1929 was associated with higher AAA spending. The coefficient on the swing vote measure was a positive and significant determinant of public works and relief spending. The F-statistics in the first stage are 4.73 for public works and relief and 8.63 for the AAA variable, both statistically significant at the $99.9 \%$ level. The Hansen J-statistic shows that we cannot 
reject the hypothesis of no relationship between the identifying instruments as a group and the estimated error term in the final migration share equation.

\subsubsection{Instrumenting for the Within-Group Term in the Nested Logit Specification:}

The inversion of the nested logit model introduces an additional endogenous variable into the model. The term $\ln \left(s_{o j \mid g_{j}}\right)$ is endogenous if it is correlated with $\xi$. This will be the case when unobservables affecting the share of individuals choosing location $j$ also affect the share of individuals who choose $j$ conditional upon choosing one of the locations within the same state of $j$, that is, when $\ln \left(s_{o j \mid g_{j}}\right)$ is correlated with $\xi$.

Berry (1994) suggests that the number of choices within the nested group might work as an instrument for the endogenous within group term. The validity of this instrument hinges upon the assumption that the number of SEAs in a state is exogenously determined by the historical drawing of geographic boundaries. Given that the number of counties was set many years before and that Bogue combined counties into SEAs based primarily on factors that we have already controlled for in the share equation, this seems to be a reasonable assumption. $^{8}$

The intuition for the relevancy of this instrument is best understood with a simple example. When there are only two SEAs $a_{1}$ and $b_{1}$ in state $g_{1}$ the probability that $a_{1}$ is the utility maximizing choice is the probability that $a_{1}>$ $b_{1}: \frac{\exp \left(X_{a 1} \beta\right)}{\exp \left(X_{a 1} \beta\right)+\exp \left(X_{b 1} \beta\right)}$ When state $g_{2}$ contains three SEAs: $a_{2}, b_{2}$, and $c_{2}$, the probability that $a_{2}$ is the utility maximizing choice, holding all else constant, is the probability that $a_{2}>b_{2}$ and $a_{2}>c_{2}: \frac{\exp \left(X_{a 2} \beta\right)}{\exp \left(X_{a 2} \beta\right)+\exp \left(X_{b 2} \beta\right)+\exp \left(X_{c 2} \beta\right)}$

\footnotetext{
${ }^{8}$ This is a relatively stronger assumption to make in the context of the IO literature. It essentially means assuming that unobserved product characteristics will have no impact on entry. However, in a geographic context, it is easier to believe that high draws of the $\xi$ term does not cause new geographic entities to "enter" the choice set.
} 
a smaller number: Thus, we anticipate that the $\ln \left(s_{o j \mid g_{j}}\right)$ variable would be negatively related with the number of SEAs in a state. Are instrument is positive and highly significant in the first stage estimation.

\subsubsection{Further Controls for Unmeasured Heterogeneity Across SEAs:}

There may be features of the SEAs that are observable to the migrants for which we have no measures, denoted $\xi$ in the model. We observe households from many origins $o$ choosing whether or not to migrate to each SEA. By taking the means for all observations for an SEA that have that SEA origin, we can use a mean-differencing approach to control the unobservable features that influence the utility of staying in that SEA $(\xi \circ o)$. Recall the econometric equation given for the inversion of the conditional logit.

$$
\ln \left(\frac{s_{o j}}{s_{o o}}\right)=\left(X_{o j}-X_{o o}\right) \beta+\left(\xi_{o j}-\xi_{o o}\right)
$$

For each origin $o$, we sum this expression over locations $j$ and scale by $\frac{1}{J-1}$ (465, the number of locations outside of the origin):

$$
\begin{aligned}
\frac{1}{J-1} \sum_{j \neq o} \ln \left(\frac{s_{o j}}{s_{o o}}\right) & =\frac{1}{J-1} \sum_{j \neq o}\left[\left(X_{o j}-X_{o o}\right) \beta+\left(\xi_{o j}-\xi_{o o}\right)\right] \\
\overline{\ln \left(\frac{s_{o j}}{s_{o o}}\right)} & =\left(\overline{X_{o j}}-X_{o o}\right) \beta+\left(\overline{\xi_{o j}}-\xi_{o o}\right)
\end{aligned}
$$

Subtracting this term from equation the 21 results in the econometric specification for fixed effects estimation: 


$$
\begin{aligned}
\ln \left(\frac{s_{o j}}{s_{o o}}\right)-\overline{\ln \left(\frac{s_{o j}}{s_{o o}}\right)} & =\left[\left(X_{o j}-X_{o o}\right) \beta+\left(\xi_{o j}-\xi_{o o}\right)\right]-\left[\left(\overline{X_{o j}}-X_{o o}\right) \beta+\left(\overline{\xi_{o j}}-\xi_{o o}\right)\right] \\
& =\left(X_{o j}-\overline{X_{o j}}\right) \beta+\xi_{o j}-\overline{\xi_{o j}}
\end{aligned}
$$

The mean differencing operation results in elimination of both observables and unobservables of the origin from the specification. This operation helps obtain consistent estimates of the $\beta$ parameters because one possible source of endogeneity, correlation between $\xi_{o o}$ and $X_{o o}$ has been eliminated.

The fixed effects estimator for the nested logit inversion is nearly identical to the fixed effect estimator for the conditional logit inversion. The only difference is that we must also include a mean differenced within group share term.

$$
\ln \left(\frac{s_{o j}}{s_{o o}}\right)-\overline{\ln \left(\frac{s_{o j}}{s_{o o}}\right)}=\left(X_{o j}-\overline{X_{o j}}\right) \beta+\sigma \cdot\left[\ln \left(s_{o j \mid g_{j}}\right)-\overline{\ln \left(s_{o j \mid g_{j}}\right)}\right]+\xi_{o j}-\overline{\xi_{o j}}
$$

\subsubsection{Heteroscedasticity and Clustering:}

It can be shown that there is covariance between the error terms that share a common origin. Because of this, our estimates of the standard errors on the parameters of our model may be inconsistent. To address this problem, we cluster standard errors for observations sharing a common origin.

\subsubsection{Dealing with "Zero Shares":}

One issue of concern in the estimations is the prevalence of origin-destination pairs for which no migrations are observed. This is problematic in our model, because we must take the log of the share of individuals choosing this destination, and natural log of zero is undefined. To avoid this problem, the value 0.0000001 was added to all of the shares before they were logged. 


\section{Results}

The nested logit specification of the model is estimated using both Ordinary Least Squares (OLS) and Two-Stage Least Squares (2SLS). The results are reported in the first two columns of Table 2. The attractiveness of the different New Deal Grants are quite different for the AAA farm payments and the public works and relief expenditures. In both the OLS and the IV estimations, an increase in AAA spending per farm population in the SEA has a negative and statistically significant impact on the utility of living there. On the other hand, IV estimates of the effect of an increase in public works and relief grants increased the SEA's attractiveness. These results are similar to the findings by Fishback, Horrace, and Kantor (2006) in analysis of net-migration between 1930 and 1940 at the county level. Their analysis was tightly constrained by the absence of information on flows between locations and jurisdictions, which limited what they could say about in-migration and out-migration decisions.

The OLS estimate of the parameter measuring the correlation of the terms for choices in a given state is .233 , which is statistically significant. Although this would imply that the CLOGIT model is not the correct specification, a positive bias in the OLS estimate of $\boldsymbol{\square}$ is anticipated because the share of individuals choosing to locate in destination SEA j, conditional upon migrating to that state is expected to be positively correlated with the overall share of individuals moving to SEA j. Additionally, we would expect that unobservables that increase the share of individuals choosing $\mathrm{j}$ conditional upon choosing j's state would also positively effect the overall share of people choosing $\mathrm{j}$. When we instrument for the within state share term, the estimate of sigma is cut sharply to a value of 0.016 , which is not statistically significantly different from 0. Therefore, when performing the computation for the marginal effects and counterfactuals, we insert a value of zero in for sigma while using the remaining 


\section{NLOGIT parameters. ${ }^{9}$}

Many of the socioeconomic features of the SEAs have the expected influence on the SEA's attractiveness. Households were more likely to choose SEAs that were nearer, had experienced less of a downturn between 1929 and 1933, had greater economic activity in the form of retail sales purchases and crop values per capita in the peak year of 1929, experienced fewer layoffs per capita in 1930, had higher populations in 1930 and experienced greater population growth in the 1920s. The main surprises were the positive effect of greater unemployment in 1930 and the absence of a strong effect of the Dust Bowl. ${ }^{10}$

\subsection{Marginal Effects of Program Spending on Migration Patterns}

The point estimates in this model provide intuition about whether the characteristics make the SEA more or less attractive to households. Given the logistic character of the model and the large number of flows between SEAS, the point estimates cannot be read as marginal effects. The parameters of the random utility function instead can be used to examine three types of marginal effects of the spending of an additional dollar of New Deal spending per capita: retention, creation, and diversion. People who otherwise would have migrated are retained in origin area $o$ if the increase in program spending in area $o$ causes them to remain in area $o$ rather than to migrate. Migration to area $o$ is created when the increase in spending causes people who otherwise would have remained in their origin SEA $j$ to choose instead to migrate to area $o$. Finally, migration

\footnotetext{
${ }^{9}$ When the value of sigma is not statistically significantly different from 0 , the NLOGIT specification is essentially the same as the CLOGIT specification with the inclusions of an additional irrelevant variable. Thus the CLOGIT results do not differ significantly from the NLOGIT results, and are available upon request from the authors.

${ }^{10}$ We have performed the analysis on migration patterns for blacks as well as for people living on farms in 1935. Similar to the findings for all people, the qualitative results for these groups showed that public works and relief spending promoted in-migration and AAA spending promoted out-migration.
} 
is diverted to area $o$ when the spending increase in area $o$ causes people who otherwise were migrating to another destination $k$ to move instead to destination $o$. Thus, if we consider the overall effect of program spending on the level of net migration to an SEA, retention is a decrease in out-migration, while the sum of diversion and creation is an increase in in-migration.

Table 1 shows the formulas for calculating the marginal retention, creation, and diversion effects associated with a one dollar per capita increase in spending by a New Deal program. Consider the effects for the Boston SEA, denoted with subscript $o$ in Table 1. The retention effect is associated with people who would have normally migrated from Boston but now stay in Boston due to a change in program spending. This is a reduction in out-migration as people substitute staying at home for migration. The marginal retention effect varies for each SEA based on the share of people in the SEA choosing to stay home. Specifically, the share of people retained is calculated as the coefficient $\beta$ of New Deal spending per capita multiplied by the share of people from Boston staying in Boston $\left(s_{o o}\right)$ multiplied by one minus that same share $\left(1-s_{o o}\right)$. This value is then multiplied by the number of people in Boston in $1930\left(N_{o}\right)$ to convert the change in share into the change in the number of people retained.

The increase in the number of in-migrants Boston from any given SEA $k$ as a result of a dollar increase in per capita program spending in Boston is calculated by multiplying the New Deal coefficient $\beta$ by the share of people from SEA $k$ moving to Boston $\left(s_{o k}\right)$, by one minus that same share $\left(1-s_{o k}\right)$, and by the number of people in SEA $k$ in $1930\left(N_{k}\right)$. To get the total increase in the number of in-migrants to Boston from all other SEAS, sum the number from each SEA $k$ across all of the SEAS except Boston.

The increase in in-migrants is the sum of the creation and diversion effects. The creation effect captures people who would not have migrated without the 
increase in spending, but who are pulled out of their home SEAs and choose to migrate to Boston in response to the rise in New Deal spending there. The share of in-migrants created is found by multiplying the New Deal coefficient $\beta$ by the share of people from $k$ who choose to stay in $k\left(s_{k k}\right)$ and by the share of people in $k$ who choose to move to Boston $\left(s_{k o}\right)$. By multiplying this number by the population of SEA $k\left(N_{k}\right)$, we obtain the total number of migrations from $k$ to Boston. Summing this term over all SEAs beside Boston gives the total number of migrants to Boston who would have stayed home in the absence of the additional spending in Boston.

Migration diversion to Boston consists of people who were already migrating to another SEA (say Providence) but switch to Boston in response to the rise in New Deal spending there. To compute the share of individuals from origin $k$ who are diverted from Providence to Boston, the New Deal coefficient $\beta$ is multiplied by the share of individuals from SEA $k$ who choose to migrate to Providence and by the share of individuals from SEA $k$ who choose to migrate to Boston. Multiplying this number by the population of SEA $k$, we obtain the total number of migrants from SEA $k$ who are diverted from Providence to Boston. After calculating this figure for origin $k$ for all SEAs other than Boston and $k$, we sum over all those SEAs to obtain the total number of households from origin $k$ who are diverted to Boston. To find the total amount of diversion to Boston for people migrating out of all origin SEAs, we compute the preceding figure for all SEAs other than Boston and sum across all those origins. ${ }^{11}$

Since the marginal effects are determined in part by the migration shares, the marginal effects are different for each SEA. A list for each SEA is available from the authors. Table 3 and Figures 4 and 5 show the averages of the marginal

\footnotetext{
${ }^{11}$ If we sum the creation effect for all SEAs and sum the retention effect for all SEAs, the two sums will be equal. This occurs because of adding up restrictions caused by the fact that internal migration flows are zero-sum. Flows out of one SEA become flows into another SEA. For a mathematical proof see Appendix II.
} 
effects on migration flows as a percentage of the population for the SEAs in each of the nine Census sub-regions for Public Works and Relief, as well as the average of the raw effect on population flows into these regions. Table 4 and Figures 6 and 7 present the same figures for the effect of the AAA.

The regions where migration rates were most responsive to a marginal dollar of New Deal spending were New England, the Mid Atlantic Region, the East North Central Region, the East South Central Region, and South Atlantic Region (see Figure 4 and the top part of Table 3). An additional dollar of public works and relief spending per capita in the average SEA in these five regions kept 0.053 to 0.069 percent of the 1930 population from out-migrating, created new in-migration from other SEAs of 0.037 to 0.091 percent of the population, and diverted enough migrants from other SEAs to these ones to raise in-migration by another 0.003 to 0.009 percent of the 1930 population. The total effect on net migration was between 0.092 to 0.166 percent. The effects in these five census regions stand in contrast to the effects in the other four more western regions, where a marginal increase in public works and relief spending only reduced outmigration from 0.013 to 0.033 percent, created in-migrants from 0.029 to 0.032 percent, diverted migrants at a rate from 0.001 to 0.002 percent, and had a total effect on net migration of between 0.045 to 0.067 percent.

We focus on migration rates because differences in population in the subregions influence the migration flows. Figure 5 and the middle section of Table 3 give a sense of how big the average migration flow was created, diverted or prevented by an additional dollar per capita in public works and relief spending. The largest average effect for sub-regions was in the Middle Atlantic region, which includes New York, Pennsylvania and Delaware. An additional dollar per capita of public works and relief spending increased prevented an average of 215 people from out-migrating from the typical Mid-Atlantic sub-region, diverted 
25 migrants into that sub-region and attracted 315 new migrants from other sub-regions. The flows in the western states were much lower, both because of lower migration rates and lower base populations.

In contrast to the effect of public works and relief, the AAA effects on netmigration are negative. The relative impact of AAA spending on migration creation, diversion, and retention rates are shown in Figures 6 and 7 and Table 4. As was the case with the public works, the creation and retention effects are substantially larger than the diversion effects of migration. The national means in Table 4 and Figures 6 and 7 show that the negative AAA retention effect in this case contributed to out-migration of 146 people or 0.06 percent of the base population. The negative mean creation effect implies that an added dollar per capita of AAA spending stopped 146 people or $0.071 \%$ of the base population from migrating into the region (Todd: why are the percentages different when the flows are the same). The added AAA dollar,diverted another 11 people, or -.005 percent of the population away from the typical sub-region.

There is a similar East-West divide in the magnitude of the marginal impact of AAA spending per capita on migration rates, although the AAA effect was negative.. An additional dollar of AAA spending per person on farms in the four western regions decreased net migration rates between 0.066 to 0.097 percent, while decreasing net migrations rates in the more eastern regions from 0.134 to 0.241 percent in Table 4 .

The East-West contrast in the findings for net migration rates suggest that eastern households considered the remaining SEAs in their region to be closer substitutes to their own SEA than did households in SEAs in the west. Actual in-migration and out-migration rates in the eastern SEAs were lower than those of western SEAs: of the nine census regions, the four western regions had the four highest rates of in-migration, and the three highest out-migration rates. 
These two sets of facts are consistent with a situation where people in the east considered many SEAs to be similar to their own 1935 SEA and thus saw little reason to move unless there was an external policy change that would widen the differential between SEAs. In the west, on the other hand, there was much greater variation in the unobservables that caused people to be more likely to move, so that a single dollar change in New Deal spending did not generate as much of a response.

\subsection{Policy Simulations}

In addition to estimating the marginal effects of a change in a variable on migration flows, we can also estimate what migration patterns would have looked

like under various counterfactuals. In such a simulation, we can set $\stackrel{\circ}{X}_{o j}$ to a counterfactual value, and compute estimated out-migration flows for each SEA $o$ to each destination $j$.

$$
\stackrel{\circ}{s o}_{j o}=\frac{\exp \left(\stackrel{\circ}{X}_{j o} \hat{\beta}\right)}{\sum_{j=1}^{J} \exp \left(\stackrel{\circ}{X}_{j o} \hat{\beta}\right)}
$$

By multiplying the estimated shares by the population and then summing across all destinations we find the number of out-migrants for each SEA. And then sum across all SEAs to obtain the total number of households out-migrating for the entire country.

$$
\stackrel{\circ}{M}=\sum_{j=1}^{J} \sum_{o=1}^{J} \stackrel{\circ}{s}_{j o} * N_{o}
$$

Since all out-migrants are in-migrants elsewhere, this would also be equal to the total number of in-migrants. We then obtain the number of migrants in each of the three counterfactual settings by inserting zero for the relevant New Deal spending. The benchmark for our counterfactual analysis is the number of 
migrations predicted by the model at the actual levels of New Deal spending.

Table 5 presents the results of our counter factual estimations. While the migration rates in the IPUMS 5\% sample imply a total of over 9 million total migrations between SEAs from 1935 to 1940, the model with actual New Deal spending predicts a total of 6.5 million out-migrations of households. Removing only the AAA grants leads to a modest increase of about 63,000 migrations, or a $1 \%$ increase in migrations. Removing public works and relief spending, on the other hand, leads to a prediction of only 5,802,387 migrations, a decrease of $12 \%$ from the predicted amount with all New Deal spending. Nearly an eighth of all migrations that took place in the in the United States from 1935 to 1940 were a direct result of the way in which public works and relief grants were distributed. Had these programs not existed, or had policy makers distributed funds in such a way that per-capita levels of funding were equal across SEAs, only $88 \%$ of migrants would have continued to move.

If New Deal spending on both the AAA and public works and relief had been completely eliminated, there would have been 5,807,415 migrations, which is 12 percent fewer migrations than the predicted number with the full amount of New Deal spending. Note that the highly interactive nature of the flows of households between SEAs leads to a combined effect of New Deal grant spending that is different from the sum of the separate AAA and public works and relief effects.

\section{Conclusion}

The simulations from a structural model of migration flows between state economic areas during the Second New Deal show that the uneven distribution of New Deal grant spending helps account for approximately 12 percent of the migration flows witnessed between 1935 and 1940. The majority of the effect 
is associated with the broad range in per capita spending on public works and relief by the federal government. As found by Fishback, Horrace, and Kantor (2006) in studies restricted to net migration rates by county, public works and relief tended to increase migration into a state economic area and reduce outmigration from the area. The AAA programs designed to restrict farm acreage contributed to a small degree of out-migration. The overall effect of the AAA on mobility was relatively small and positive.

These effects appear to be large relative to the effects found for modern migration in response to differences in welfare spending. There are several potential reasons for these differences. First, the distribution of spending in the 1930s was much less tightly tied to matching formulas that force states to spend more to obtain more welfare funding. The negotiations between Congress and the Roosevelt administration in passing the Social Security Act of 1935 ensured that the permanent federal/state public assistance programs, like old-age assistance, aidto-the-blind, and aid to dependent children required matching formulas. This matching grant feature imposed constraints on differences across states, as a state who sought higher expenditures had to dip into their own revenues as well. The compromise meant that the Roosevelt administration obtained much greater control over the emergency relief funds distributed under the WPA and public works programs that ended during World War II (Wallis, Fishback, and Kantor 2006). Studies at the time show that despite the presence of de jure matching formulas in the WPA, the formulas appear to have been ignored in fact (Howard, 1943). Thus, the range in spending per capita was much larger. Second, the unemployment and underemployment rates during the 1930s were several orders of magnitude larger than in the modern era and the standard of living was lower. Therefore, the same amount of federal spending in the 1930s as in the modern era was a larger share of the person's average income. Much 
of the spending was designed to put people explicitly back to work and in the case of public works spending required movement by some people to relatively less populated areas. 


\section{References}

[1] Allard, Scott; Danziger, Sheldon (2000). "Welfare magnets: myth or reality?", The Journal of Politics, 62: 350-368.

[2] Alston, Lee (1981). "Tenure choice in Southern agriculture", Explorations in Economic History, 18: 211-232.

[3] Anderson, Gary M.; Robert D. Tollison (1991). "Congressional influence and patterns of New Deal spending, 1933-1939", Journal of Law and Economics, 34: 161-75.

[4] Bartel, Ann P (1989). "Where do the new U.S. immigrants live?", Journal of Labor Economics, 7: 371-391.

[5] Berry, Steven T (1994). "Estimating discrete-choice models of product differentiation", The RAND Journal of Economics, 25: 242-262.

[6] Biles, Roger (1994). The South and the New Deal. University of Kentucky Press, Lexington, KY.

[7] Blank, Rebecca (1998). "The effect of welfare and wage levels on the location decisions of female-headed households", Journal of Urban Economics, 24: $186-211$.

[8] Bogue, Donald (1951). State economic areas: A description of the procedure used in making a functional grouping of the counties of the United States. U.S. Bureau of the Census. Washington, D.C.: Government Printing Office.

[9] Bogue, Donald ; Beale, Calvin (1953). "Economic Subregions of the United States", Farm Population. Series Census-BAE, No. 19. Washington, D.C. Government Printing Office.

[10] Bogue, Donald.J.; Shyrock Jr., H.S.; Hoermann, S.A; (1957) Subregional migration in the United States, 1935-40. Volume I, Streams of Migration Between Subregions. Scripps Foundation, Oxford, OH.

[11] Borjas, George J.; Bronars, Stephen G.; Trejo, Stephen J (1992). "SelfSelection and Internal Migration in the United States." Journal of Urban Economics, 32: 159-185.

[12] Brown, Josephine Chapin (1940). Public Relief, 1929-1939 Henry Holt and Company, New York, NY.

[13] Cardell, Scott (1997). "Variance components structures for extreme-value and logistic distributions with application to models of heterogeneity", Econometric Theory, 13: 185-213.

[14] Couch, Jim, Atkinson, Keith E.; Wells, William H. (1998). "New Deal agricultural appropriations: a political influence", Eastern Economic Journal, 24: $137-48$. 
[15] Couch, Jim; Shughart II, William (1998). The political economy of the New Deal. Edward Elgar, New York, NY.

[16] Couch Jim; Williams, Peter M. (1999). "New Deal or same old shuffle? The distribution of New Deal dollars across Alabama", Economics and Politics, 11: 213-223.

[17] Cragg, Michael; Kahn, Matthew (1997). "New estimates of climate demand: evidence from location choice", Journal of Urban Economics, 42: 261-284.

[18] Federal Works Agency, Work Projects Administration. Final Statistical Report of the Federal Emergency Relief Administration (Washington, DC: GPO, 1942).

[19] Fishback, Price V., Haines, Michael R.; Kantor, Shawn (2001). "The impact of New Deal programs on black and white infant mortality in the South", Explorations in Economic History, 38: 93-122.

[20] Fishback, Price V.; Horrace, William C.; Kantor, Shawn (2006). "Do federal programs affect internal migration? The impact of New Deal expenditures on mobility during the Great Depression", Explorations in Economic History, 43: 179-222.

[21] Fishback, Price V.; Horrace, William C.; Kantor, Shawn (2005a). "Do federal programs affect internal migration? The impact of New Deal expenditures on mobility during the Great Depression", NBER Working paper No. w8283. Jan 2005.

[22] Fishback, Price V.; Horrace William C.; Kantor, Shawn (2005b). "The impact of New Deal expenditures on local economic activity: an examination of retail sales, 1929-1939", Journal of Economic History, 65: 36-71

[23] Fishback, Price V., Kantor, Shawn; Wallis, John Joseph (2003) "Can the New Deal's Three Rs be rehabilitated? A program-by-program, county-bycounty analysis", Explorations in Economic History, 40: 278-307.

[24] Fleck, Robert Kenneth (1994). "Essays on the political economy of the New Deal", unpublished Ph.D. dissertation, Stanford University.

[25] ___ (2001a). "Inter-party competition, intra-party competition, and distributive policy: a model and test using New Deal data", Public Choice, $108: 77-100$.

[26] _ _ _ (2001b). "Population, land, economic conditions, and the allocation of New Deal spending", Explorations in Economic History, 38: 296304.

[27] ____(1999a). "The marginal effect of New Deal relief work on countylevel unemployment statistics", Journal of Economic History, 59: 659-87. 
[28] _ turnout on distributive policy", Economic Inquiry, 37: 609-23.

[29] Gramlich, Edward; Laren, Deborah (1984). "Migration and income redistribution responsibilities", Journal of Human Resources, 19: 489-511.

[30] Herzog, Henry W., Jr.; Schlottmann, Alan M.(1986). "The metro-rating game: what can be learned from recent migrants?" Growth and Change, 17: $37-50$.

[31] Holley, William C.; Winston, Ellen; Woofter, Thomas Jackson (1971). The Plantation South, 1934-1937. Freeport, NY, Books for Library Press.

[32] Howard, Donald S (1943). The WPA and Federal Relief Policy. Russell Sage Foundation, New York, NY.

[33] Jaeger, D.A. (2000). "Local Labor Markets, Admission Categories, and Immigrant Location Choice" Mimeo, Hunter College and Graduate School of CUNY, New York and IZA, Bonn.

[34] Kauffman, Kyle; Kiesling, Lynne (1997). "Was there a nineteenth entury welfare magnet in the United States? Preliminary results from New York City and Brooklyn.", The Quarterly Review of Economics and Finance, 37: 439-448..

[35] Levine, Phillip; Zimmerman, David (1999). "An empirical analysis of the welfare magnet debate using the NLSY", Journal of Population Economics, 12: 391-409.

[36] McFadden, Daniel (1973). "Conditional logit analysis of qualitative choice behavior", in P.Zarembka, ed., Frontiers in Econometrics, Academic Press, New York.

[37] Mertz, Paul E (1978). New Deal policy and Southern rural poverty. Louisiana State University Press, Baton Rouge, LA.

[38] Moffitt, Robert (1992). "Incentive effects of the U.S. welfare system: a review", Journal of Economic Literature, 30: 1-61.

[39] Reading, Don C. (1973). "New Deal activity and the states, 1933 to 1939", Journal of Economic History, 1973: 792-810.

[40] Roy, A. D. (1951). "Some thoughts on the distribution of earnings." Oxford Economic Papers, 3: 135-146.

[41] Rhode, Paul; Strumpf, Koleman (2003). "Assessing the importance of Tiebout sorting: local heterogeneity from 1850 to 1990", American Economic Review, 93: 1648-77.

[42] Saloutos, Theodore (1974). "New Deal agricultural policy: an evaluation", The Journal of American History, 61: 394-416. 
[43] Schaefer, Donald F (1989). "Location Choice in the Antebellum South", The Journal of Economic History, 49: 145-165.

[44] Sjaastad, Larry A (1962). "The costs and returns of human migration", The Journal of Political Economy, 70: 80-93.

[45] Strömberg, David (2004). "Radio's Impact on Public Spending". Quarterly Journal of Economics, 119: 189-221.

[46] U.S. Office of Government Reports, Statistical Section, 1940. Report No. 10, Volume 1, "County reports of estimated federal expenditures" March 4, 1933 - June 30, 1939'. Mimeo.

[47] Wallis, John; Fishback, Price; Kantor, Shawn (2006). "Politics, relief, and reform: Roosevelt's efforts to control corruption and political manipulation during the New Deal." in Corruption and Reform Edward Glaeser and Claudia Goldin eds. NBER Volume. Chicago: University of Chicago Press: 343-372.

[48] Wallis, John Joseph; Benjamin, Daniel K (1981). "Public relief and private employment in the Great Depression", Journal of Economic History, 41: 97-102.

[49] Wallis, John (1987). "Employment, politics, and economic recovery during the Great Depression", Review of Economics and Statistics, 69: 516-20.

[50] _____(1998). "The political economy of New Deal spending revisited, again: with and without Nevada", Explorations in Economic History, 35: 140-70.

[51] _ _ (2001). "The political economy of New Deal spending, yet again: a reply", Explorations in Economic History, 38: 305-14.

[52] Webb, John N (1936). "The transient unemployed", Monthly Report of the Federal Emergency Relief Administration January 1 through January 31, 1936 (Washington, DC: GPO, 1936), 1-25.

[53] Whatley, Warren C (1983). "Labor for the picking: the New Deal in the South", The Journal of Economic History, 45: 905-929.

[54] Williams, Edward Ainsworth (1968). Federal Aid for Relief. AMS Press, New York.

[55] Wright, Gavin (1974). "The political economy of New Deal spending: an econometric analysis", Review of Economics and Statistics, 56: 30-38. 


\section{Appendix I: Inversion of Nested Logit in Our Model}

Berry derives the inversion of the nested logit model as follows:

$$
\begin{gathered}
s_{o j}=s_{o j \mid g_{j}} * s_{g_{j}} \\
s_{o j \mid g_{j}}=\frac{\exp \left(\frac{\delta_{o j}}{1-\sigma}\right)}{D_{g_{j}}} \\
s_{g_{j}}=\frac{D_{g_{j}}^{1-\sigma}}{\left[\sum_{j \in G_{g}} D_{g_{j}}^{1-\sigma}\right]} \\
D_{g_{j}}=\sum_{j \in G_{g}} \exp \left(\frac{\delta_{j}}{1-\sigma}\right)
\end{gathered}
$$

There are two key simplifying assumptions Berry makes to derive the inversion of the nested logit model:

a) The utility of the outside good is normalized to 0 , which does not hold for our model

b) The outside good is the sole member of its group, which does not hold for our model

These assumptions imply:

$$
s_{o o}=s_{g_{0}} * 1=\frac{1}{\left[\sum_{j \in G_{g}} D_{g_{j}}^{1-\sigma}\right]}
$$

The share ratios can then be expressed as:

$$
\begin{gathered}
\frac{s_{j}}{s_{o}}=\frac{\exp \left(\frac{\delta_{j}}{1-\sigma}\right)}{D_{g_{j}}} \frac{D_{g_{j}}^{1-\sigma}}{\left[\sum_{j \in G_{g}} D_{g_{j}}^{1-\sigma}\right.} /\left[\frac{1}{\left[\sum_{j \in G_{g}} D_{g_{j}}^{1-\sigma}\right]}\right]=\frac{\exp \left(\frac{\delta_{o j}}{1-\sigma}\right)}{D_{g}} \\
\ln \left(s_{o j}\right)-\ln \left(s_{o o}\right)=\frac{\delta_{o j}}{1-\sigma}-\ln \left(D_{g_{j}}\right)
\end{gathered}
$$

Going back to equation 29, we see

$$
s_{g_{j}}=\frac{D_{g_{j}}^{1-\sigma}}{\left[\sum_{j \in G_{g}} D_{g_{j}}^{1-\sigma}\right.}=D_{g_{j}}^{1-\sigma} * s_{o o} \Rightarrow \ln \left(s_{g_{j}}\right)=(1-\sigma) * \ln \left(D_{g_{j}}\right)+\ln \left(s_{o o}\right)
$$

Solving for $\ln \left(D_{g}\right)$ and plugging into equation (7) 


$$
\ln \left(s_{o j}\right)-\ln \left(s_{o o}\right)=\delta_{j}+\sigma * \ln \left(s_{j \mid g}\right)
$$

Because there is more than one choice in the outside good's group (also we do not normalize the utility of the outside good to 0 , but that is not the key difference between Berry and the migration problem):

$$
\begin{gathered}
s_{g_{o}}=\frac{D_{o}^{1-\sigma}}{\left[\sum_{j \in G_{g}} D_{g_{j}}^{1-\sigma}\right]} \\
s_{o o}=s_{g_{o}} * s_{o \mid g_{0}}=\frac{\exp \left(\frac{\delta_{o 0}}{1-\sigma}\right)}{D_{0}} \frac{D_{0}^{1-\sigma}}{\left[\sum_{j \in G_{g}} D_{g}^{1-\sigma}\right]}
\end{gathered}
$$

So equation 32 now becomes:

$\frac{s_{o j}}{s_{o o}}=\frac{\exp \left(\frac{\delta_{o j}}{1-\sigma}\right)}{D_{g}} \frac{D_{g}^{1-\sigma}}{\left[\sum_{j \in G_{g}} D_{g}^{1-\sigma}\right]} /\left[\frac{\exp \left(\frac{\delta_{o o}}{1-\sigma}\right)}{D_{o}} \frac{D_{o}^{1-\sigma}}{\left[\sum_{j \in G_{g}} D_{g}^{1-\sigma}\right]}\right]=\frac{\exp \left(\frac{\delta_{o j}}{1-\sigma}\right)}{\exp \left(\frac{d_{o o}}{1-\sigma}\right)} *\left(\frac{D_{g_{j}}}{D_{o}}\right)^{-\sigma}$

Taking logs,

$$
\ln \left(s_{o j}\right)-\ln \left(s_{o o}\right)=\frac{\delta_{o j}-\delta_{o o}}{1-\sigma}-\sigma *\left[\ln \left(D_{g_{j}}\right)-\ln \left(D_{o}\right)\right]
$$

Taking the log of equation 30 and 10, respectively, we now have

$$
\begin{aligned}
\ln \left(D_{g_{j}}\right) & =\frac{\ln \left(\left[\sum_{j \in G_{g}} D_{g}^{1-\sigma}\right]\right)+\ln \left(s_{o j}\right)}{1-\sigma} \\
\ln \left(D_{o}\right) & =\frac{\ln \left(\left[\sum_{j \in G_{g}} D_{g_{j}}^{1-\sigma}\right]\right)+\ln \left(s_{o o}\right)}{1-\sigma}
\end{aligned}
$$

Subtracting these two terms,

$$
\ln \left(D_{g_{j}}\right)-\ln \left(D_{o}\right)=\frac{\ln \left(s_{g_{j}}\right)-\ln \left(s_{o o}\right)}{1-\sigma}
$$

Which gives us (as the differencing of the deltas is equivalent to normalizing the utility of the outside good to 0) the same results at Berry:

$$
\ln \left(s_{o j}\right)-\ln \left(s_{o o}\right)=\delta_{o j}-\delta_{o o}+\sigma *\left(\ln _{j \mid g_{j}}\right)
$$




\section{Appendix II: Symmetry of Creation and Retention}

One complication we face in reporting marginal effects is the choice of which marginal effect to report. As the $s$ variable varies across observations, a different estimation of the marginal effect can be computed at each observation One natural solution to this problem would be to report the mean of all estimated marginal effects. However, as we show below, this approach also results in a serious complication.

Consider again the migration retention term in Table 1 . Table 1 expresses the number of migrants retained in location $o$ as the number of individuals in the $o$ who substitute to location $o$ when a characteristic of $o$ changes (own effects):

$$
\text { retention }_{o}=N_{o}\left(1-s_{o o}\right) * s_{o o} * \beta
$$

Another way in which we can think of this term is as the number of people in

$o$ who substitute away from every other possible choice when a characteristic of $o$ changes (summing over cross effects)

$$
\text { retention }_{o}=\sum_{j \neq o} N_{o} s_{o o} s_{o j} \beta
$$

Now consider the measure of creation in Table 1.

$$
\text { creation }_{o}=\sum_{j \neq o} N_{j} * s_{j j} s_{j o} * \beta
$$

Suppose that we want to find the average amount of retention. This would

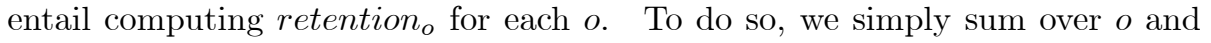
divide by the number of choices in the set:

$$
\overline{\text { retention }}=\frac{\sum_{o} \sum_{j \neq o} N_{0} s_{o o} s_{o j} \beta}{J}
$$

To find the average amount of creation, we do the same operation to creation $_{o}$ :

$$
\overline{\text { creation }}=\frac{\sum_{o} \sum_{j \neq o} N_{j} * s_{j j} s_{j o} * \beta}{J}
$$

Note this symmetry: the set containing the $N_{j} * s_{j j} s_{j o}$ term for every possible $j$ and $o$ will be identical to the set containing $N_{0} s_{o o} s_{o j}$ for every possible value of $o$ and $j$. Thus, the average effects of retention and creation will be identical if we sum over all observations. To obtain more intuitive results, we instead estimate averages of the marginal effects for each of the 9 census regions. 


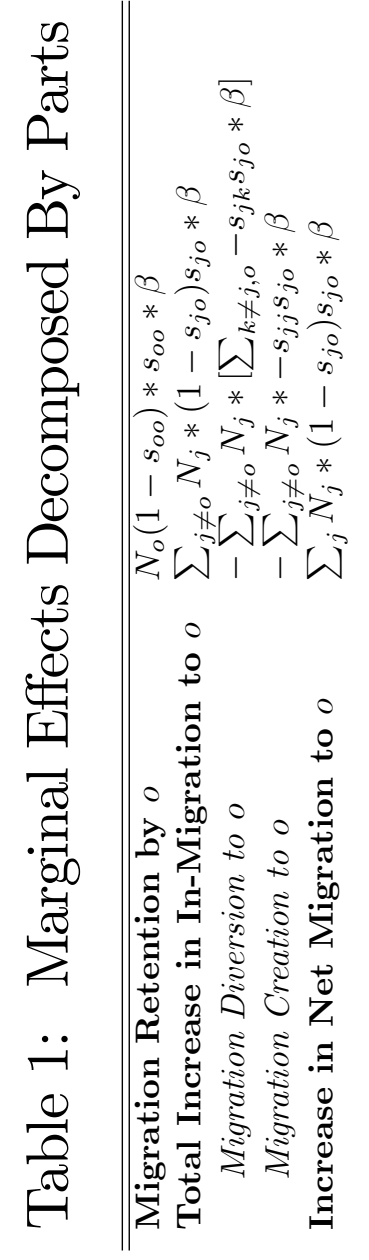




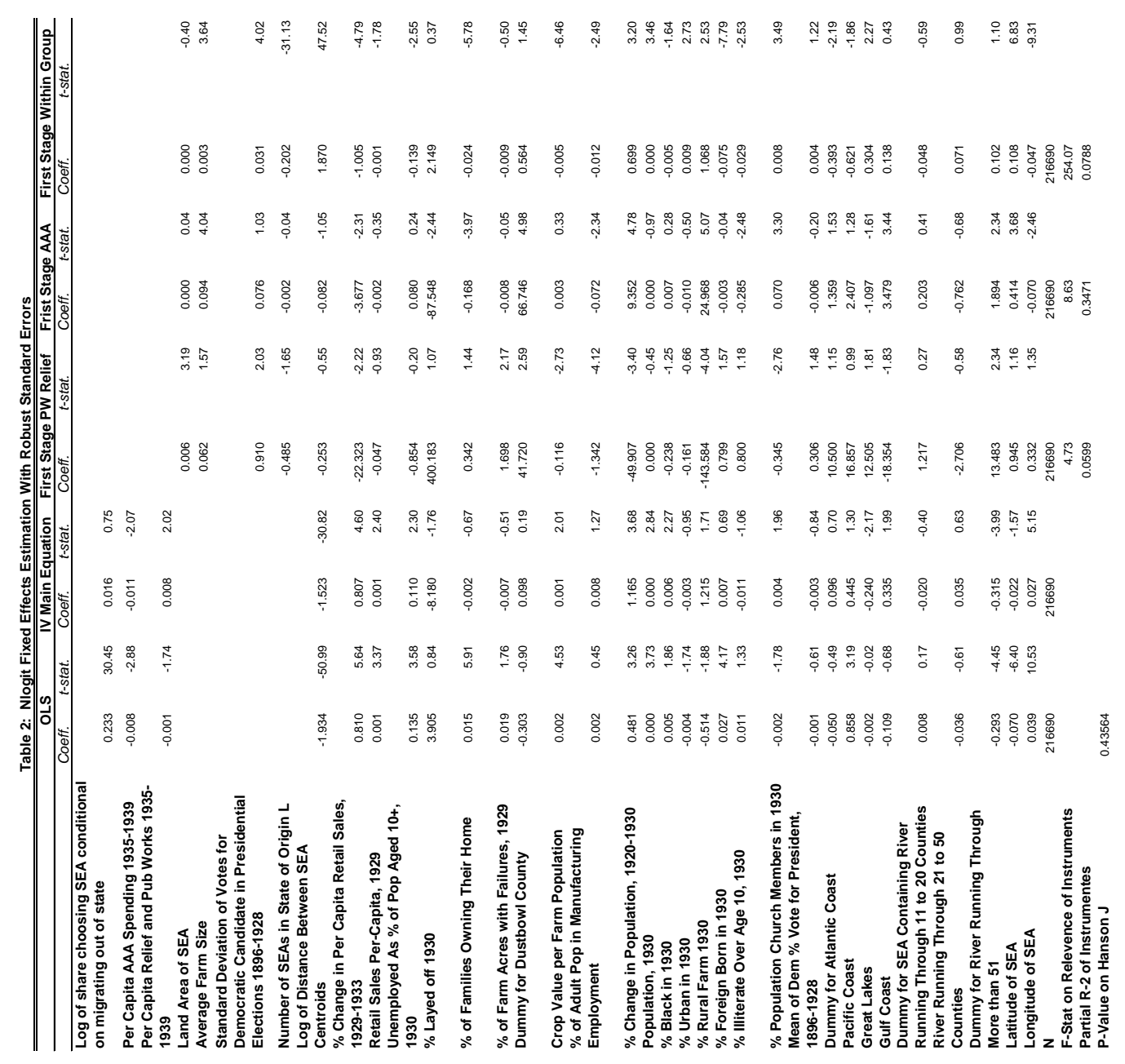




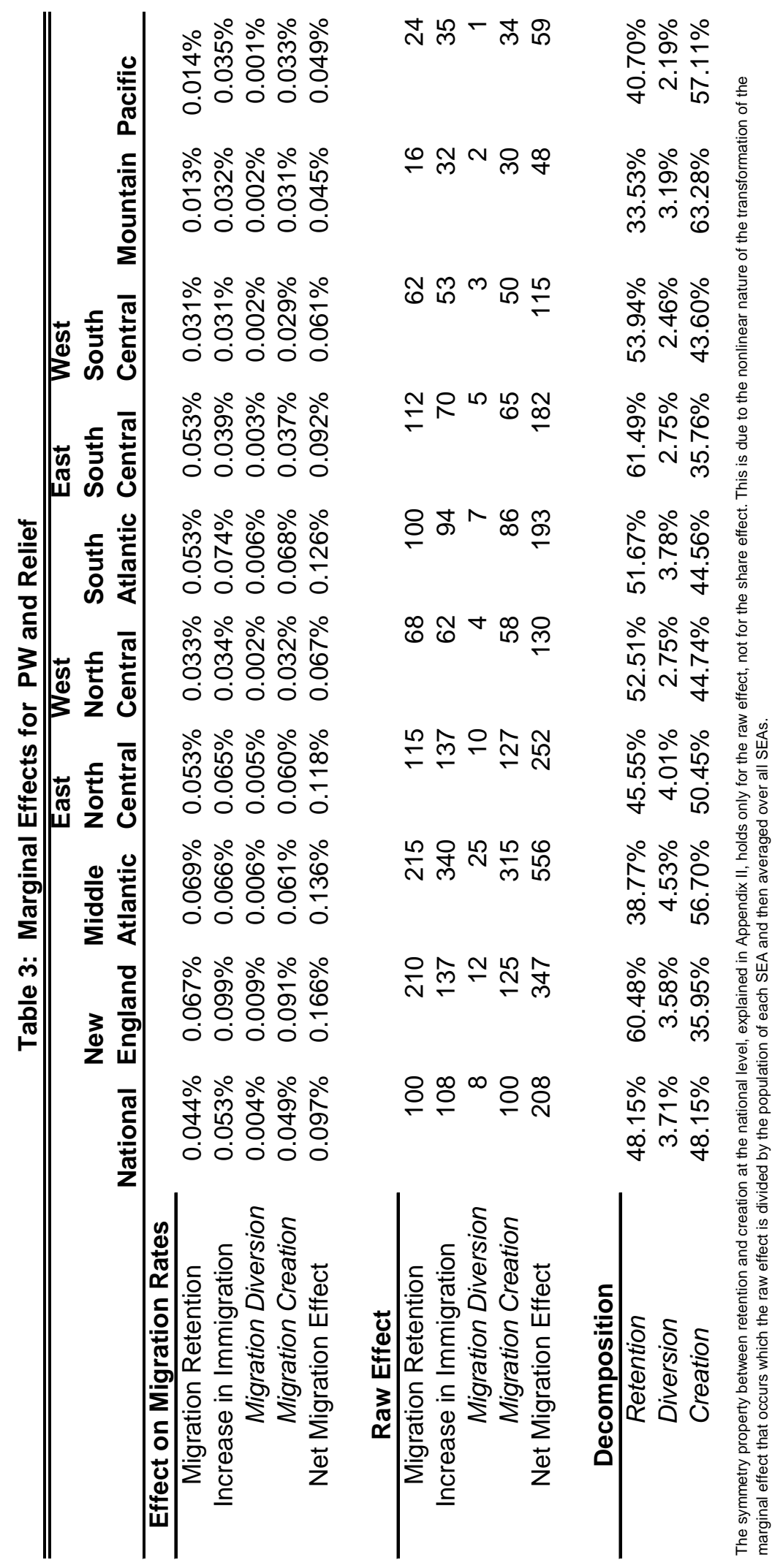




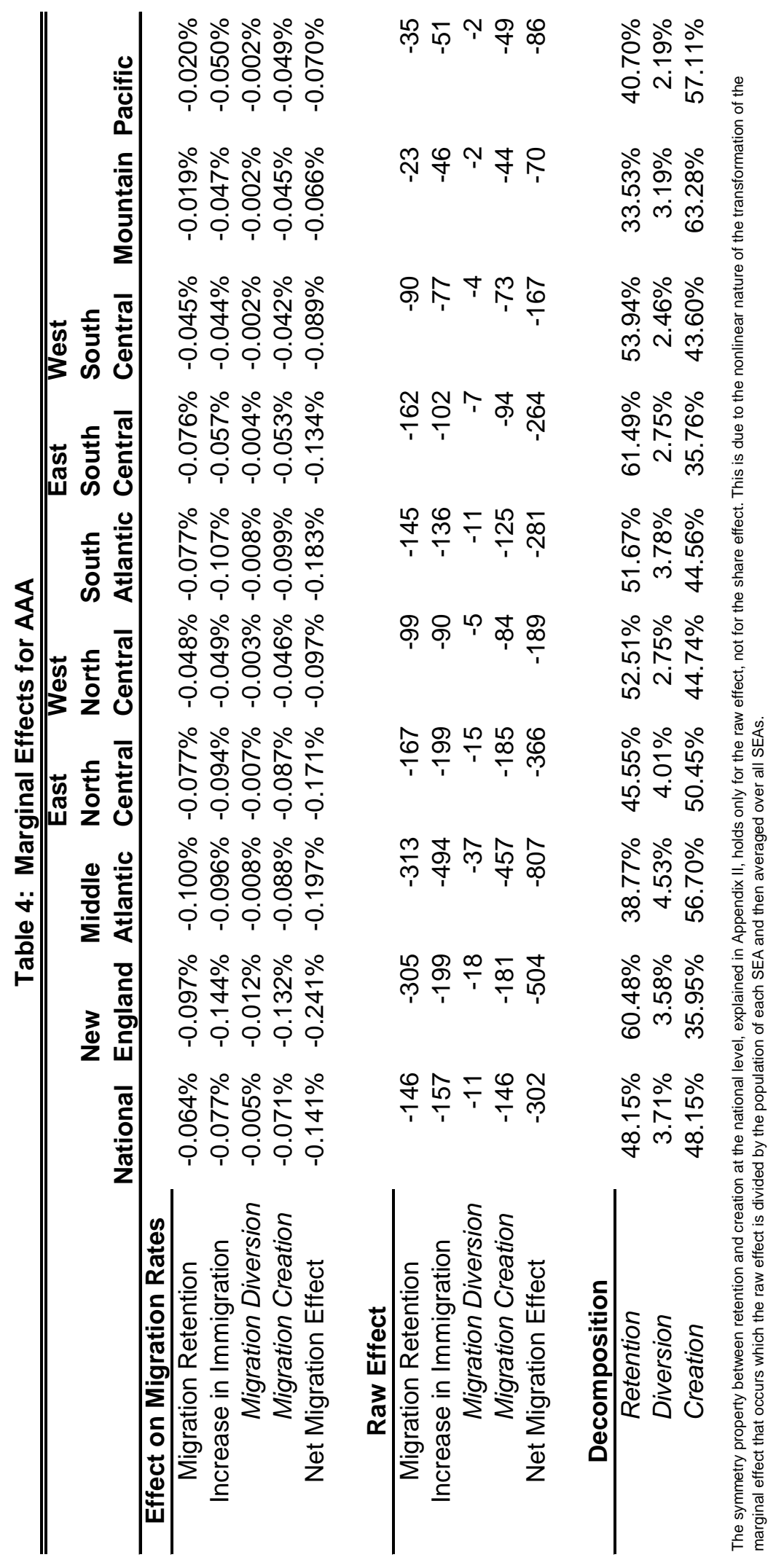




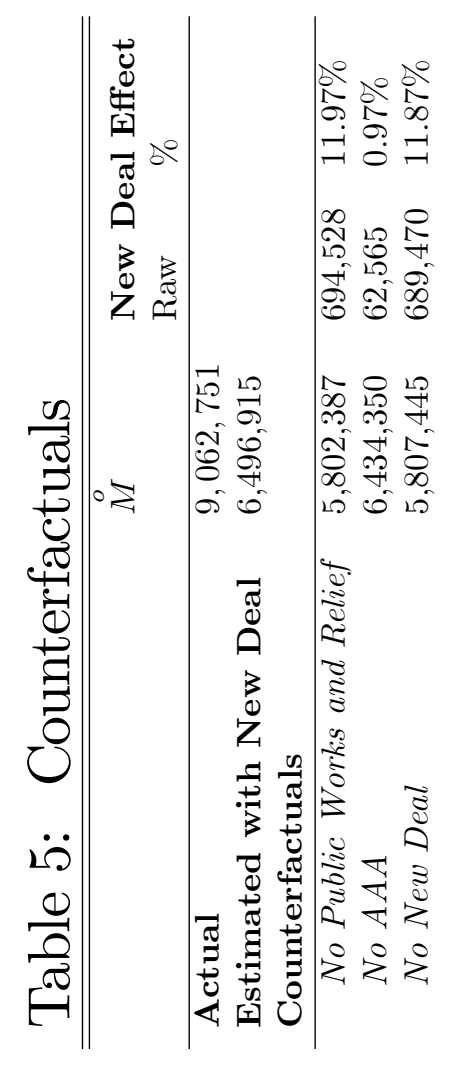




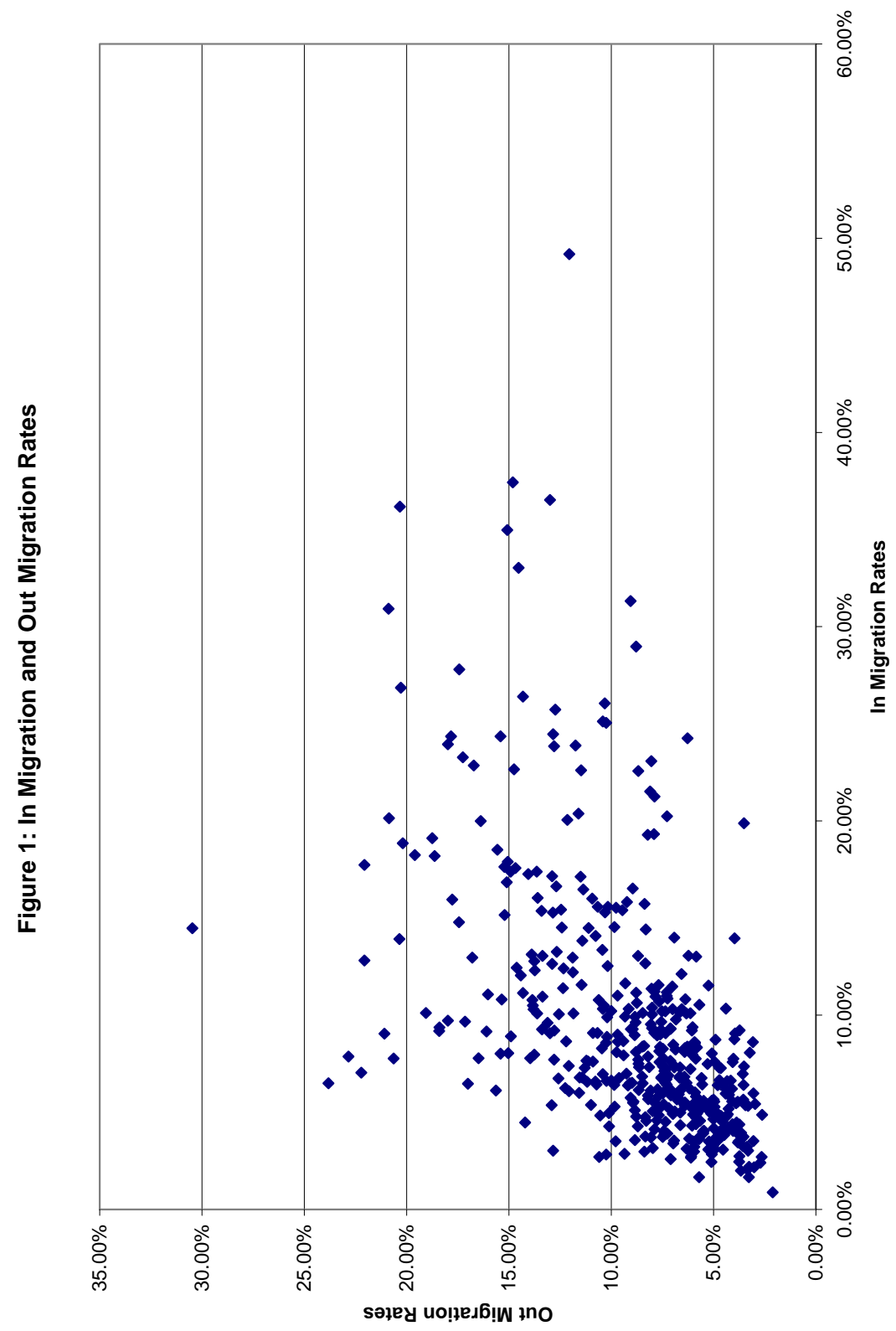

52 


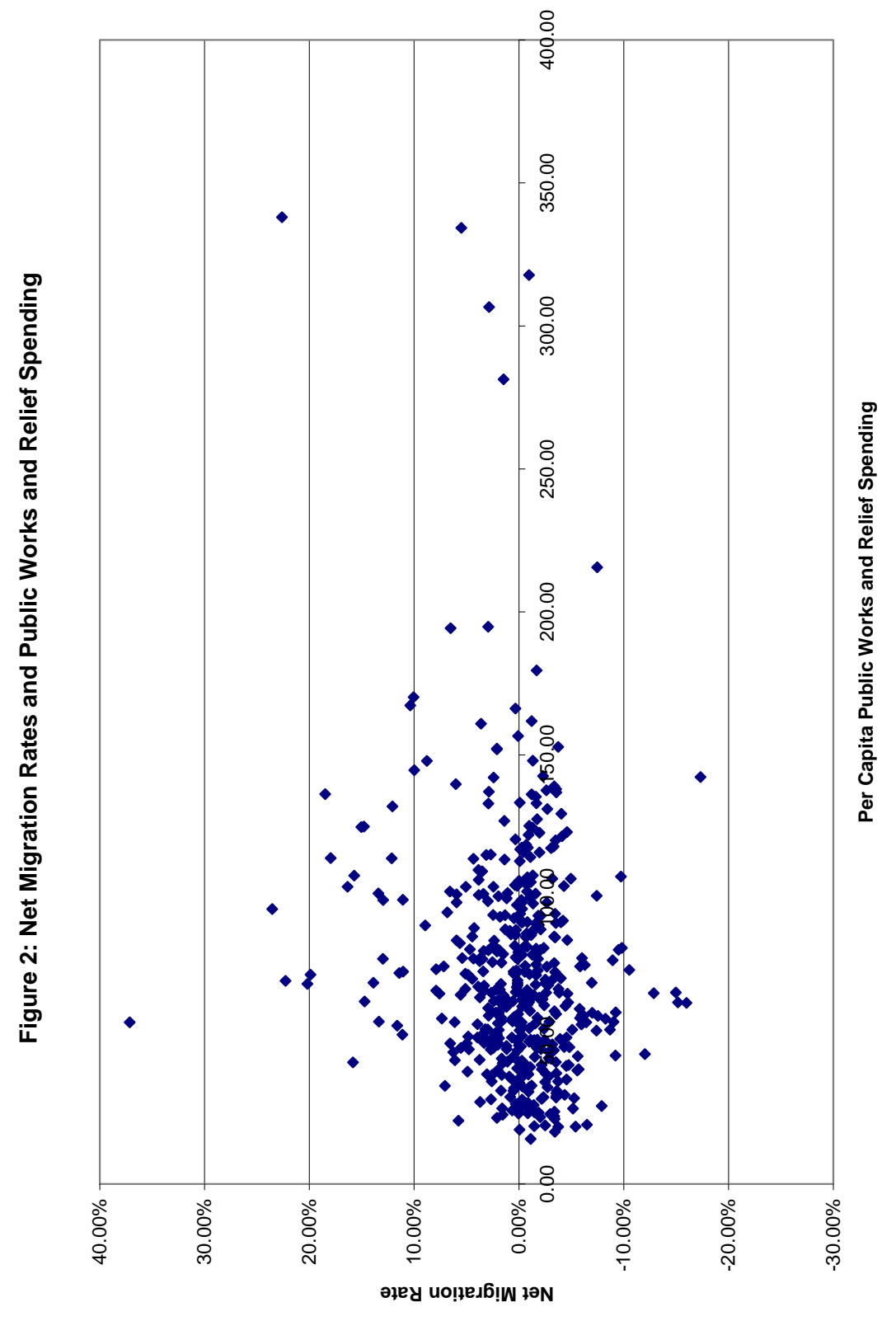




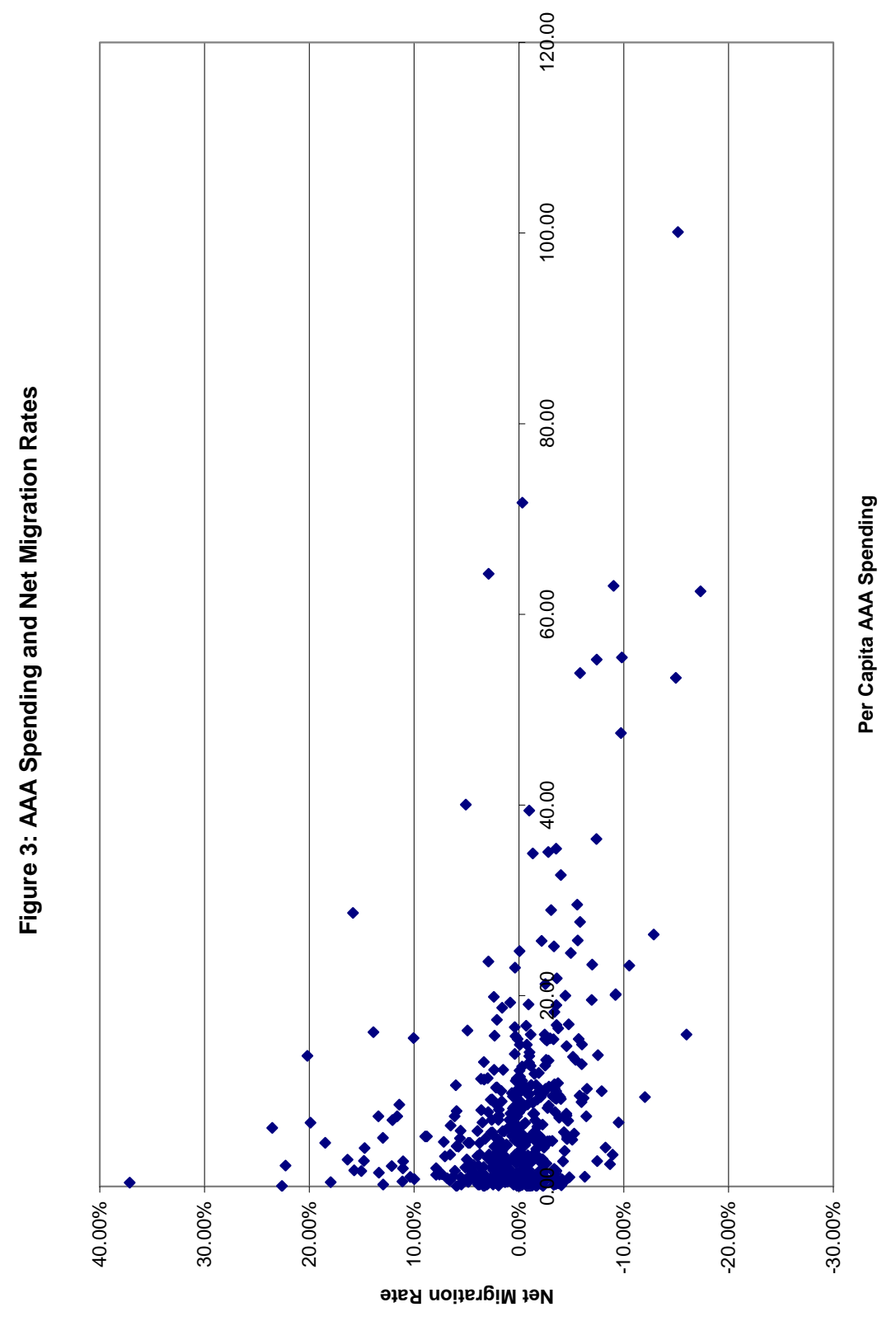




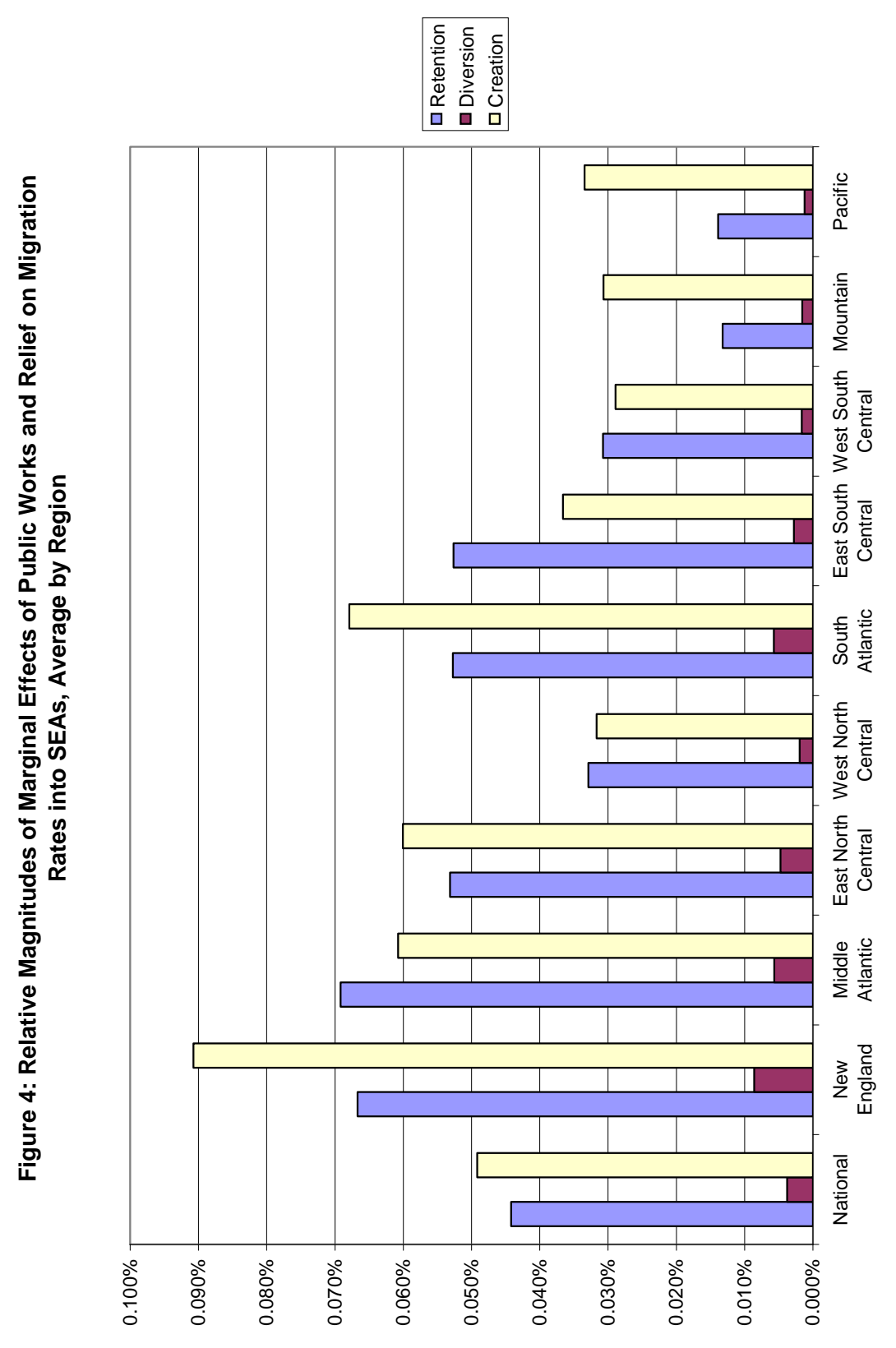




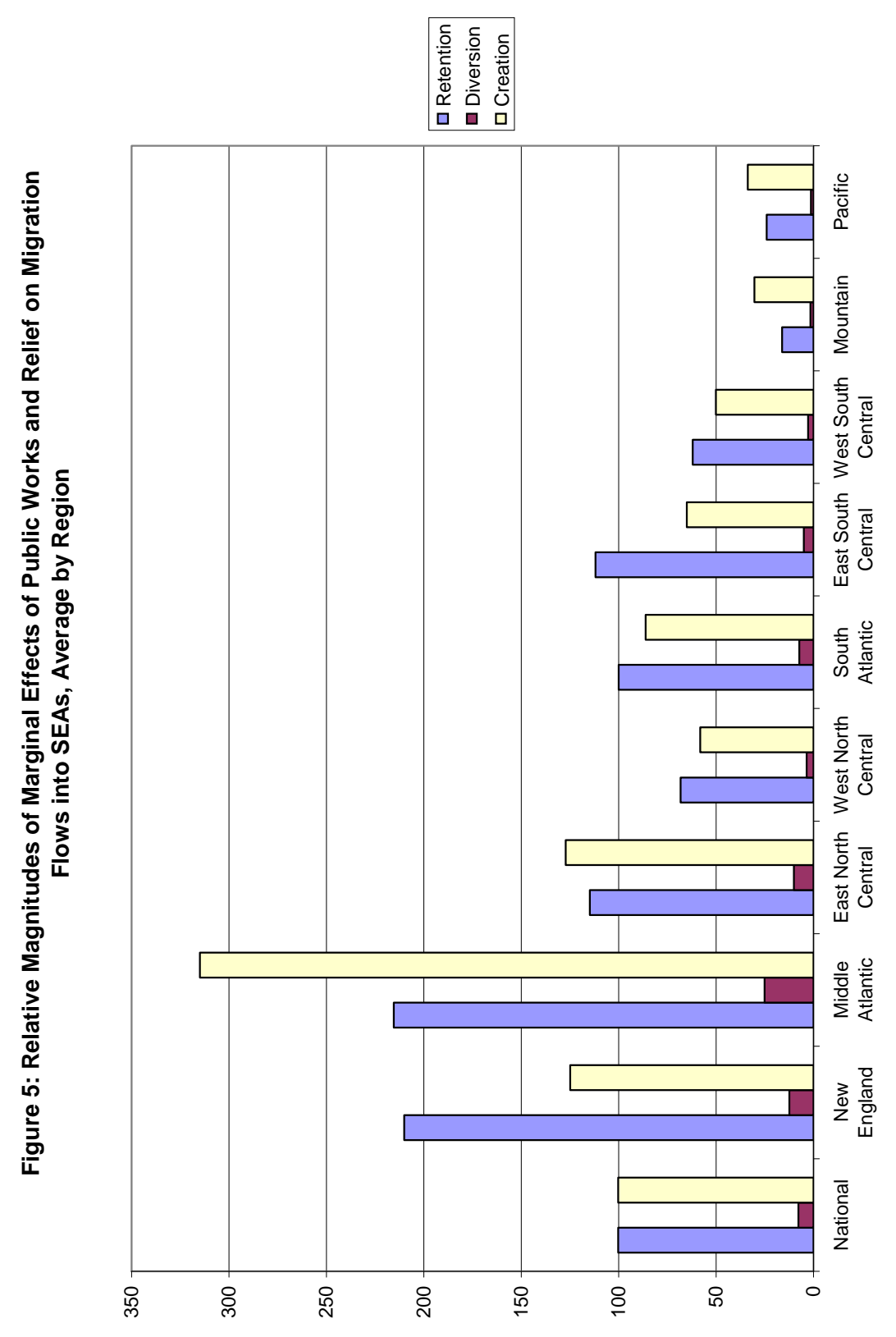




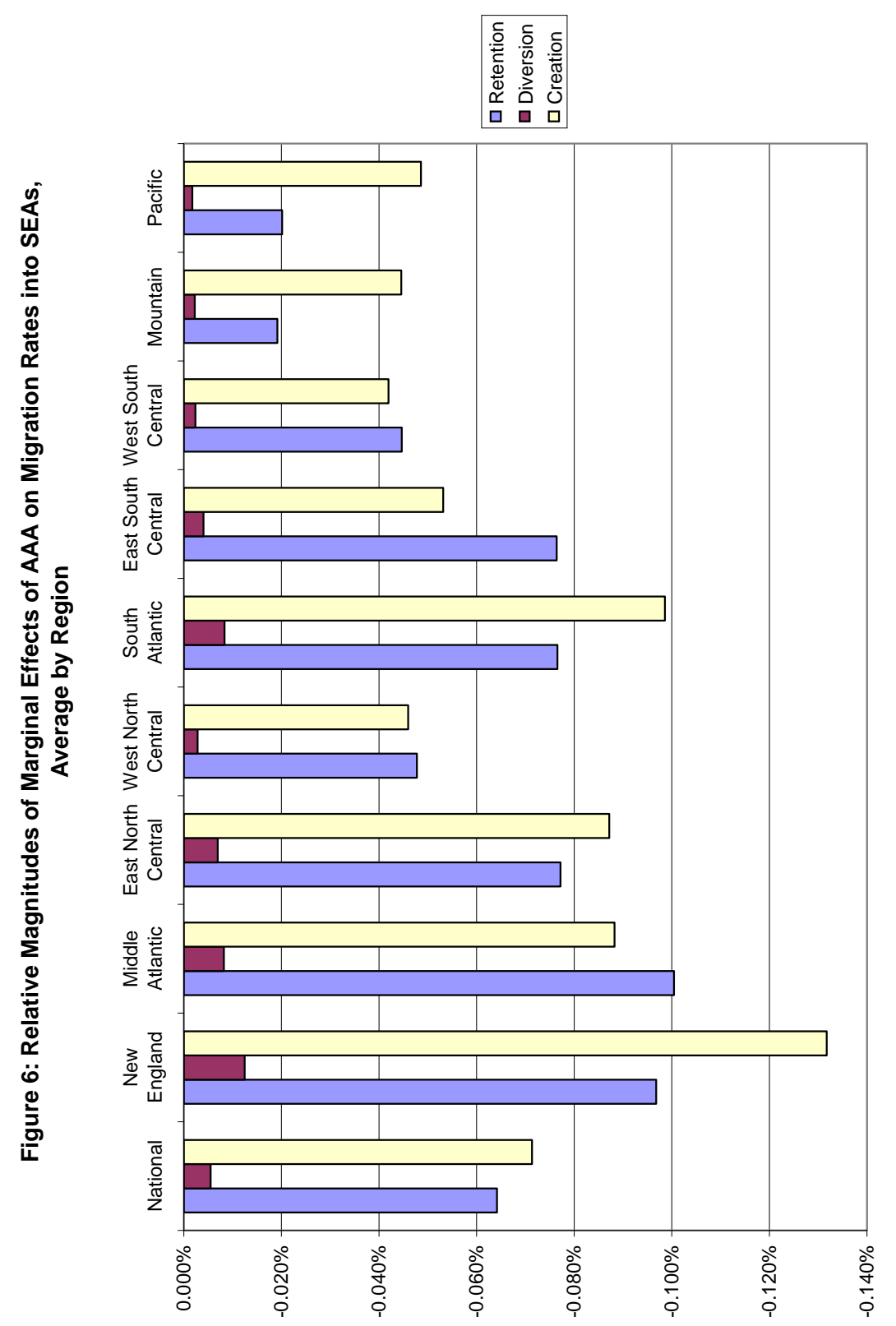




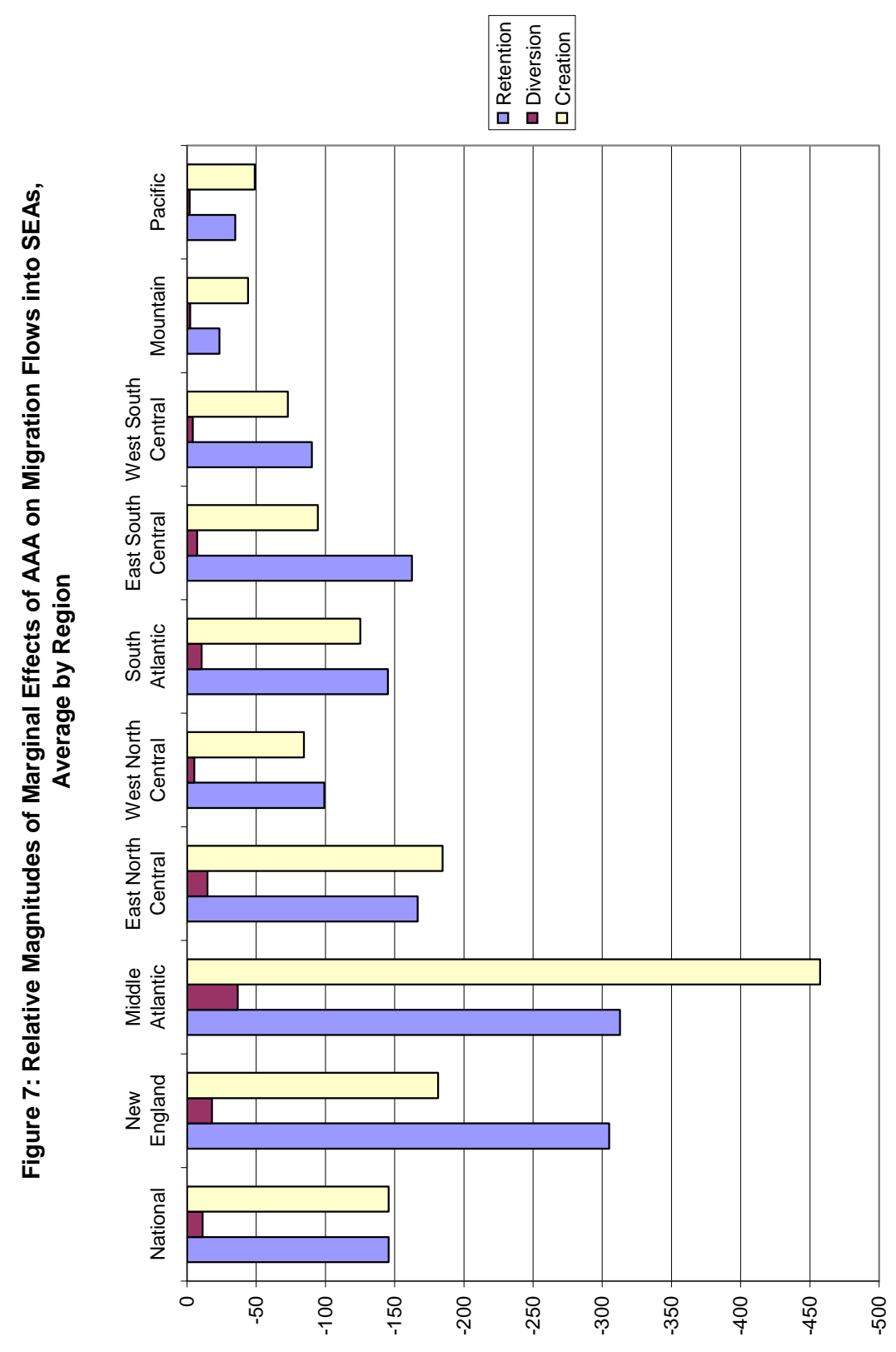

